\title{
IX. Scheinblüte und Fehlschlagen der Kollaboration 1940
}

\author{
1. „Abetz était complètement gagné“: \\ Kontaktaufnahme zu Pierre Laval
}

Vichy, 14. Juli 1940. In der mondänen Bäder-Stadt wimmelte es von Politikern, Regierungsbeamten und Militärs. Schaulustige bevölkerten die Straßen, die Gerüchteküche brodelte. Hierher hatte es den greisen Staatschef Marschall Pétain und sein Gefolge auf der Flucht vor Hitlers Armeen verschlagen, in Hotels und Kursälen bezogen sie Quartier. Republik und parlamentarische Demokratie waren Vergangenheit, die Weichen für einen autoritären ,Etat français' gestellt ${ }^{1}$.

Auch Jacques Nels bahnt sich an diesem 14. Juli einen Weg durch die Menschenmenge vor Pétains provisorischem Amtssitz, dem „Hôtel du Parc“. Er sucht seine Kollegen von der Presse-Agentur Agence Radio. Durch Zufall erfährt er, daß sein früherer Chef bei Notre Temps, Jean Luchaire, in Kürze eintreffen wird. Nels beschließt zu warten. Luchaire ist in Eile, weil verabredet mit dem stellvertretenden Ministerpräsidenten Pierre Laval, akzeptiert aber dankbar das Angebot, sich für eine Nacht das Hotelzimmer zu teilen. Freie Betten sind rar in Vichy. Nach der Audienz präsentiert er - ganz der alte - ein Bündel Banknoten. Laval hat es ihm zugesteckt und ihn beauftragt, unverzüglich nach Paris zu fahren, um im Gespräch mit Ribbentrops Statthalter Otto Abetz die deutschen Absichten zu erkunden. Nels rät dringend ab: „Du riskierst viel!“ Doch Luchaire läßt sich die Mission nicht ausreden: Es sei ein Gebot der Stunde, freundschaftliche Bande zu nutzen und Frankreichs Möglichkeiten gegenüber den Besatzern auszuloten².

Vor Gericht hat Luchaire den Sondierungsversuch ausführlich geschildert. An seinem Wohnsitz in der Avenue des Ternes war eine Nachricht seiner ehemaligen Sekretärin Suzanne Abetz vom 25. Juni hinterlegt: „Cher Monsieur, Otto aimerait beaucoup vous voir dès votre retour à Paris. Vous pourrez le joindre ici, rue de Lille." Als Luchaire telefonisch um einen Termin bat, stellte sich freilich heraus, $\mathrm{da}$ a an diesem Nachmittag bereits Laval in der Botschaft erwartet wurde. Er war schneller als sein Emissär zu Abetz vorgedrungen, was dem Umstand zuzuschreiben ist, daß sich zuvor schon zwei andere Mittelsmänner bemüht hatten, den Boden zu bereiten: Jean Fontenoy und Fernand de Brinon, auch sie langjährige Vertraute des Deutschen ${ }^{3}$. Den Stein ins Rollen brachte Fontenoy, und zwar auf Geheiß von Abetz, der ebenfalls brennend an einer Kontaktaufnahme interessiert

1 Der Sturz der ,Dritten Republik' wird ausführlich geschildert bei Aron, Histoire de Vichy, Kap. II und III; Bloch, L'étrange defaite; Warner, Laval, Kap. VI; Kupferman, Laval, S. 228 ff.; Shirer, Zusammenbruch, Kap. 36 und 37.

2 Nels, Fragments, S. 186 ff. Luchaire hat den Sachverhalt bestätigt. Lavals erste Frage lautete: „Etes-vous toujours bien avec Abetz?“ Les procès de collaboration, S. 370.

3 Ebenda, S. $371 \mathrm{ff}$. 
war und ausrichten ließ, daß er zu Gesprächen mit hochrangigen Vichy-Politikern bereitstehe ${ }^{4}$. Voller Ungeduld setzte Laval daraufhin zunächst Brinon in Marsch, der beim ersten Anlauf an der Demarkationslinie abgewiesen wurde und erst im zweiten nach Paris gelangte. In der Botschaft übermittelte er Lavals Wunsch, in einen Dialog einzutreten. Abetz und Schleier signalisierten persönliches Entgegenkommen, dämpften aber insgesamt die Erwartungen: Die Berliner Führung sei überwiegend feindselig gestimmt. Immerhin durfte Brinon fortan ungehindert als Kurier zwischen Vichy und Paris verkehren ${ }^{5}$. Wenige Tage später, am 19. Juli, war es dann soweit: Abetz begrüßte Laval zu einem ersten Gedankenaustausch. Rasch entwickelte sich daraus eine Verbindung, die beiden Männern das Gefühl gab, den idealen Verhandlungspartner gefunden $\mathrm{zu}$ haben. Vor dem Hintergrund des Kriegsverlaufs im zweiten Halbjahr 1940 fielen sie der Illusion anheim, Wegbereiter einer weitreichenden Zusammenarbeit zwischen Siegern und Besiegten sein zu können, die den jeweiligen Interessen Rechnung tragen würde.

Der aus bescheidenen Verhältnissen stammende, mit allen politischen Wassern gewaschene Auvergnat Pierre Laval (1883-1945) hatte seine Karriere 1914 als Pazifist und sozialistischer Abgeordneter begonnen; 1919 stimmte er gegen den Versailler Vertrag. 1923 wurde der gelernte Jurist Bürgermeister im Pariser ArbeiterVorort Aubervilliers, im darauffolgenden Jahr schaffte er erneut den Sprung ins Parlament und schwenkte alsbald zur nationalistischen Rechten über. Bis 1936 gehörte er den meisten französischen Kabinetten an, zugleich erwarb er ein stattliches Vermögen, unter anderem als Zeitungsverleger. 1931/32 stieg er zum Ministerpräsidenten auf, just als Deutschland die Fesseln des Young-Plans abzustreifen begann. Eine zweite Spanne als Regierungschef 1935/36 war überschattet von Vorwürfen, er habe Mussolini freie Hand in Abessinien gewährt. Vergeblich versuchte Laval, von vielen als skrupelloser Opportunist geschmäht, in den dreißiger Jahren ein Bündnis mit Italien zu schmieden und die Berliner Führung für multilaterale Vereinbarungen zu erwärmen; an der Notwendigkeit eines deutsch-französischen Rapprochements als solider Friedensgarantie hegte er nie einen Zweifel. Nur aus taktischen Gründen handelte er einen Pakt mit den Sowjets aus, warnte im übrigen vor der ,bolschewistischen Gefahr'. 1939 im Lager der Kriegsgegner, sah er seine Stunde gekommen, als Hitlers Armeen Frankreich überfielen und Pétain im Juni 1940 den Auftrag zur Kabinettsbildung erhielt. Beide Männer hatten gegen die Volksfront opponiert, und schon damals hatte Laval eine kritische, bisweilen feindselige Haltung zur parlamentarischen Demokratie offenbart. Nun be-

4 The Unpublished Diary of Pierre Laval, S. 70; Laval parle, S. 64; Kupferman, Laval, S. 250; Delpla, Montoire, S. 116; Déat, Mémoires politiques, S. 551. Duroselle, L'Abîme, S. 262, erwähnt einen Abetz-Brief an Laval vom 8. Juli. Eine genaue Rekonstruktion, wer wann mit wem kommunizierte, ist schwierig, weil die Angaben der Beteiligten schwanken. Auch sonst scheinen die Überlieferungen nicht immer präzise. So behauptet Bertrand de Jouvenel, am 14. Juli 1940 in Paris gewesen zu sein (Voyageur, S. $376 \mathrm{ff}$.), während Nels sich erinnert, ihn an jenem Tag in Vichy getroffen und aus seinem Mund von der Ankunft Luchaires gehört zu haben.

5 Autobiographische Aufzeichnung „Fernand de Brinon 1940-1945“, o.D.; AN, 411 AP 6. Ders., Mémoires, S. $20 \mathrm{ff}$. Les procès de collaboration, S. 87, 180; Aron, Histoire de Vichy, S. $261 \mathrm{ff}$. 
trieb er behende den Sturz der morschen Republik, auch um selbst an die Schalthebel der Macht zu gelangen und im Glauben, eine autoritäre Regierungsform könnte sich gegenüber den Diktaturen besser behaupten. Er wurde stellvertretender Ministerpräsident in Vichy und designierter Nachfolger von Staatschef Pétain und versuchte umgehend Einfluß auf das deutsch-französische Verhältnis zu gewinnen. Niemand sei berufener als er, meinte Laval, sich unter Wahrung der französischen Interessen mit den Besatzern zu arrangieren. Dabei vertraute er auf sein Verhandlungsgeschick und das direkte Gespräch von Mann zu Mann. Triebfeder seines Handelns war neben persönlichem Ehrgeiz die Überzeugung, daß Deutschland auch Großbritannien besiegen und den Krieg gewinnen werde, weshalb Frankreich an einer zielstrebigen Zusammenarbeit mit dem Reich gelegen sein mußte. Von diesem Kurs erhoffte sich Laval Erleichterungen des Waffenstillstandsregimes, milde Friedensbedingungen und eine vorteilhafte Rolle seines Landes im , neuen', nationalsozialistisch dominierten Europa ${ }^{6}$.

Dieser Ansatz paßte trefflich in Abetz' Konzept, aus Frankreich einen willigen, dafür wohlgelittenen Satelliten des Reiches zu formen. In der Rue de Lille war man bereits auf Laval aufmerksam geworden: In einem Dossier für das Auswärtige Amt vom 13. Juli 1940 wird er als „eigentlich führender Kopf" der Vichy-Regierung gehandelt. Seiner allgemein anerkannten Geschicklichkeit zum Trotz sei er jedoch bei seinen Landsleuten umstritten. Linkskreise suchten seine moralische Autorität unter Hinweis auf dunkle Vermögensquellen zu erschüttern, während selbsternannte Erneuerer Frankreichs „ihn mit dem Makel behaftet [sehen], ein im Grunde typischer Vertreter des alten Parlamentarismus zu sein“. Das Interesse der Botschaft an einer Zusammenkunft schmälerten derlei Zeugnisse nicht, zumal sich niemand sonst in Vichy aus der Deckung zu wagen schien: „Außenpolitisch tritt die neue Regierung in geduckter Haltung auf." ${ }^{7}$ Laval dagegen tat am 14. Juli über einen seiner Mittelsmänner die Absicht kund, "nächsten Freitag" nach Paris zu kommen. Zugleich ließ er anfragen, ob ein Treffen mit Göring möglich sei, den er von der Beerdigung Pilsudskis 1935 in Krakau kannte. Darüber hinaus versuchte er sich den Deutschen ideologisch anzudienen, indem er die Gründung einer französischen Einheitspartei, die Berufung sozialistischer Gewerkschaftsführer in sein Ministerium und ein Verbot der Freimaurerei in Aussicht stellte, ebenso die Entfernung von Juden aus öffentlichen Ämtern ${ }^{8}$.

6 Siehe die einschlägigen Kapitel bei Warner, Kupferman und Cointet sowie die älteren Laval-Biographien von Hubert Cole (Paris 1964) und Alfred Mallet (2 Bde., Paris 1955). Ferner Paxton, Vichy France, S. 24 ff.; Robert Frank, Pétain, Laval, Darlan, in: Azéma/ Bédarida (Hrsg.), La France des années noires, 1, bes. S. $306 \mathrm{ff}$. Marcel Déat notierte am 3. 7. 1940, Laval erstrebe eine loyale und offene Kollaboration mit dem Sieger - die Kosten des Krieges solle England tragen; Journal de guerre, zit. bei Brender, Kollaboration, S. 88.

7 Dossier der Botschaft über das Kabinett Pétain, 13. 7. 1940, offenbar ein Entwurf; PA/ AA, Botschaft Paris 1297.

8 Abetz an Ribbentrop, 14. 7. 1940; PA/AA, R 29587. Die taktische Absicht dieser Pläne, die Laval in deutschen Augen vertrauenswürdig machen sollten, betont Jäckel, Frankreich, S. 99. Erste antijüdische Gesetze erließ die Vichy-Administration allerdings noch in der zweiten Julihälfte. 
Am Morgen des 19. Juli fuhr Legationsrat Zeitschel nach Moulins, um Laval an der Demarkationslinie zu begrüßen und nach Paris zu geleiten. Rudolf Schleier hat dem Besuch in seinen Memoiren ein eigenes Kapitel gewidmet, das Begeisterung für den Franzosen atmet und verdeutlicht, warum er über alle Wechselfälle der nächsten Jahre hinweg Abetz' Favorit für eine Politik der Kollaboration blieb ${ }^{10}$. „Mit weichem Velourshut und Spazierstock, im dunkelblauen Anzug [...] und mit der legendären weißen Krawatte betrat er die Botschaft. In der Bibliothek erwarteten wir ihn. Keiner von uns kannte ihn bisher persönlich“". Ein Aperitif wurde gereicht, anschließend bat der Hausherr zu Tisch. Während des Essens schwelgten Lavals Begleiter Brinon, Fontenoy und Henry-Haye in gemeinsamen Erinnerungen mit Abetz, Schleier und Achenbach - die Anspannung wich. Bis spät in die Nacht hinein entwickelte Laval sodann „seine Auffassung von der Lage Frankreichs und der nach seiner Meinung möglichen Rolle, die es in einem künftigen, befriedeten und unter deutscher Führung stehenden Europa einnehmen könne". Laut Schleier erkannte er die kontinentale Vormachtstellung des Reiches an und erhoffte sich eine Behandlung seines Landes, die der ruhmreichen Geschichte und dem französischen Nationalstolz Rechnung trug. Auf keinen Fall dürften Frankreich und seine Kolonien verkleinert werden ${ }^{11}$. Wenn Deutschland bereit sei, das Ausmaß seines Sieges weise zu beschränken, würden die Franzosen Seite an Seite mit den Nachbarn für den Frieden und eine bessere Zukunft arbeiten, ein Wunsch, den Marschall Pétain uneingeschränkt teile. Die Kriegserklärung an Deutschland habe er für einen Fehler gehalten, betonte Laval. Im Volk sei kein Verständnis vorhanden gewesen, „warum Frankreich wegen einer deutschen Stadt wie Danzig und des polnischen Korridors in den Krieg ziehen müsse“, was man am mangelnden Kampfeswillen der Franzosen ablesen könne. Die verantwortlichen Staatsmänner hätten das Land zudem ohne ausreichende Vorbereitung in einen neuen Waffengang gestürzt, die englischen Verbündeten keineswegs die erwartete Unterstützung geleistet. Nie und nimmer akzeptieren mochte der Gast aus Vichy den italienischen Triumph: Mussolini sei erst über Frankreich hergefallen, „als es bereits tödlich verwundet am Boden lag“. Deshalb werde man lieber zugrunde gehen, als auch nur einen Quadratmeter Boden an Italien abzutreten.

Einer solchen Sichtweise konnten und wollten sich die deutschen Diplomaten nicht entziehen, korrespondierte sie doch ganz erstaunlich mit den eigenen Vorstellungen. Die Wertschätzung des Franzosen, dessen Vorschläge die aktuelle Beschlußlage im Kabinett Pétain völlig ignorierten ${ }^{12}$, wuchs offenbar von Minute zu Minute. „Manche kleinen äußeren Dinge sprechen gegen ihn“, notierte Schleier. „Der ungepflegte schwarze Schnurrbart, die etwas aufgequollenen Lippen, die schlechten Zähne, seine wenig gepflegten Hände, die vom vielen Zigarettenrau-

9 "Bescheinigung" Schleiers vom 18. 7. 1940; CDJC, V-1.

10 "Pierre Laval“; PA/AA, Nachl. Schleier/IV.2.

11 Diesen Punkt betonte Laval auch, als er seinem Schwiegersohn über die Unterredung berichtete; R. de Chambrun, Laval devant l'histoire, S. 117f. Vgl. Abetz, Das offene Problem, S. 150: „Seine Hauptsorge galt [...] der Erhaltung der territorialen Einheit seines Vaterlandes. Um sie zu retten, war er bereit, weitgehende moralische Garantien zu geben." Siehe ferner Mallet, Laval, I, S. $214 \mathrm{ff}$.

12 Aron, Histoire de Vichy, S. 266. 
chen an den Fingerspitzen dunkelbraun gefärbt waren; die Lässigkeit des Rauchens, die ständig Asche auf Rock und Weste niederfallen ließ [...] Und doch war Laval ein Redner, der nach wenigen Sätzen das Ohr seiner Zuhörer fand [...] Es gingen von ihm die Kraft und das Fluidum einer starken Persönlichkeit aus." Mit ruhiger Stimme und sparsamen Gesten habe er es verstanden, den Kern eines Problems zu verdeutlichen und für seine Auffassung zu werben.

Soweit die Schilderung Schleiers, die sich im wesentlichen mit Otto Abetz' Angaben deckt. Nach seinen Worten offerierte Laval eine Zusammenarbeit „ohne Hintergedanken" auf französischem Boden - eine Perspektive, die sein Gegenüber elektrisierte, vordergründig aber kaum aus der Reserve lockte. Noch immer handelte Abetz ohne klare Weisung seiner Vorgesetzten und geregelten Status und konnte allenfalls spekulieren, wie die deutsche Führung mit Frankreich verfahren würde; markige Töne aus Berlin ließen eine harte Linie befürchten. Seine Bitte, die Visite als inoffizielle Fühlungnahme zu betrachten und gegenüber der Presse Stillschweigen zu bewahren, spiegelt die persönliche Verunsicherung. Er beschränkte sich auf die Zusage, umgehend Bericht zu erstatten und einige von Laval aufgeworfene Fragen - Schicksal der Flüchtlinge und Kriegsgefangenen, Versorgungslage, Besatzungskosten, Auflockerung des Verkehrs über die Demarkationslinie zur Sprache zu bringen ${ }^{13}$. „Le premier contact avec M. Abetz fut correct et assez froid“, resümierte Laval ${ }^{14}$. Das mochte äußerlich zutreffen, doch fanden die beiden nach einer kurzen Phase des Abtastens ${ }^{15}$ durchaus Gefallen aneinander. "Abetz était complètement gagné“, erzählte Luchaire, der seinen Freund unmittelbar nach dem Treffen sprach. "Même le mot , séduit' ne serait pas excessif.“16 „Peterchen“, wie Laval botschaftsintern genannt wurde, urteilte im Gegenzug über den deutschen Chefdiplomaten: „Il me plaît, c'est un paysan de la forêt noire." 17

In Vichy gab der stellvertretende Ministerpräsident seine Mission als vollen Erfolg aus. Dem amerikanischen Geschäftsträger sagte er, das Reich wolle eine Föderation europäischer Staaten, in der Frankreich eine bedeutsame Rolle zufallen solle ${ }^{18}$. Im Kabinett habe er "positiv“ und zur Zufriedenheit Pétains über die Parisreise berichtet, meldete Brinon, der ständiger Mittelsmann Lavals zur Rue de Lille wurde und alle Fragen hinsichtlich einer Wiederbelebung der deutsch-französischen Beziehungen studieren sollte ${ }^{19}$. Damit war eine Konstellation geschaf-

13 Abetz, Das offene Problem, S. 149f. Übereinstimmend bis in die Wortwahl die unsignierte Aufzeichnung eines Laval-Vertrauten vom 23. 7. 1940, aus der Abetz zitiert; AN, AJ $72 /$ 258.

14 Laval parle, S. 64.

15 Brinon, Mémoires, S. 23.

16 Les procès de collaboration, S. 373. Mit gleichem Tenor Déat, Mémoires politiques, S. 572. Abetz gab an, vor der Zusammenkunft alle gängigen Vorbehalte gegen Laval geteilt zu haben; Das offene Problem, S. 145. Es folgt eine ausführliche Würdigung des Franzosen.

17 Zit. aus Notizen Brinons; AN, 411 AP 6.

18 Murphy an State Department, 29. 7. 1940; FRUS, 1940 II, S. 378.

19 Schleier an Auswärtiges Amt, 25. 7. 1940; ADAP, D X, Nr. 226. Andere Quellen spiegeln gelindes Entsetzen in Vichy über Lavals Alleingang. Er habe nicht verhandelt, zürnte Außenminister Baudouin, sondern sich weit aus dem Fenster gelehnt und den Deutschen eine 
fen, die Frankreichs als anglophil geltenden Außenminister Paul Baudouin von Verhandlungen mit der Botschaft so gut wie ausschloß ${ }^{20}$, ebenso den Generaldelegierten für das besetzte Gebiet Noël und dessen Nachfolger de La Laurencie ein schlagendes Beispiel jener Paralleldiplomatie, die Abetz seit seiner Lehrzeit in der Dienststelle Ribbentrop virtuos beherrschte. Auch war nun ein wichtiger Draht außerhalb der militärischen Kanäle geknüpft, die bei der Waffenstillstandskommission in Wiesbaden zusammenliefen.

Davon abgesehen wollte Abetz Lavals Einfluß in Vichy offenbar erst einmal ausloten, indem er die Entlassung mißliebiger Kabinettsmitglieder verlangte. Flottenchef François Darlan erfuhr am 22. Juli aus dem Munde Lavals, daß sich das Mißtrauen gegen Erziehungsminister Mireaux und Kolonialminister Lémery richte („parce que affairistes"), ferner gegen Außenminister Baudouin („parce que homme de Paul Reynaud“) und den Kollegen für Familie und Jugend, Ybarnegaray (, ,j'ignore pour quelle raison") ${ }^{21}$. Ein Reflex der deutschen Forderungen findet sich in Schleiers Telegramm vom 25. Juli: „Schwierigkeiten innerhalb Kabinetts durch [Verteidigungsminister] Weygand und auch Ybarnegaray. Letzterem durch Laval mitgeteilt, daß er unerwünscht sei. "22 Bertrand de Jouvenel, der für den militärischen Nachrichtendienst die Absichten der Besatzer erkundete und von Abetz mit offenen Armen empfangen wurde, erkannte einen regelrechten "Test“ der Durchsetzungsfähigkeit Pétains und Lavals im eigenen Lager. Eine von ihm übermittelte ,schwarze Liste enthält die Namen Mireaux (,il représente le vieux capitalisme“), Weygand („nous ne voulons pas de von Seeckt chez vous“) und Lémery nebst der Beschwerde, daß dem einstigen Präsidenten des Comité France-Allemagne, Georges Scapini, bislang keine vertrauensvolle Aufgabe übertragen worden $\operatorname{sei}^{23}$. Zumindest das änderte sich schnell: Vom 31. Juli an durfte sich der blinde Veteran in amtlicher Mission um das Los der französischen Kriegsgefangenen kümmern; er löste in dieser Funktion den früheren Botschafter in Berlin François-Poncet ab ${ }^{24}$. Abetz' Begeisterung für Lavals Avancen war demnach von Anfang an mit einem zielgerichteten politischen Kalkül verknüpft.

Obschon der Gedankenaustausch vom 19. Juli ohne konkretes Ergebnis blieb, profitierten beide Gesprächspartner davon. Laval besaß als erstes Mitglied der

umfassende Zusammenarbeit offeriert, ohne Inhalte und Grenzen abzustecken. Baudouin, Neuf mois, S. $258 \mathrm{f}$.

20 Vergeblich hatte sich Baudouin Anfang Juli um eine diskrete Zusammenkunft etwa mit Ribbentrop bemüht. Über die spanische Regierung ließ er mitteilen, Frankreich erkenne die Niederlage an, bitte aber um ein mildes Besatzungsregime. ADAP, D X, Nr. 140. Er wurde jedoch erst Mitte September in Paris von Abetz empfangen.

21 Darlan, Lettres et notes, S. 194. Ebendort ein gespaltenes Echo auf Lavals Parisreise: „Certains disent que le voyage [...] a été un échec, les autres non. Certains prétendent que Laval est mal vu à Berlin et à Rome et qu'il constitue le principal obstacle à une amélioration de la situation."

22 Wie Anm. 19.

${ }^{23}$ Jouvenel, „Rapport du 2 août 1940 fait à Navarre et aussi remis à Pierre Laval, avec communication au maréchal Pétain", abgedruckt in ders., Voyageur, S. $391 \mathrm{ff}$.

${ }^{24}$ Scapini, Mission sans gloire, S. 21; Baudouin, Neuf mois, S. $256 \mathrm{ff}$.; ausführlich Unteutsch, Sohlbergkreis, S. 160 ff. Am 6. 9. 1940 schieden Mireaux, Lémery und Ybarnegaray aus, Weygand wurde Generaldelegierter in Nordafrika. 
Vichy-Regierung einen direkten diplomatischen Draht zu den Besatzern und sicherte sich allen Anfeindungen zum Trotz in den kommenden Monaten ein Quasi-Monopol auf diesem Feld, wiewohl die Deutschen stets auch anderen Stimmen lauschten ${ }^{25}$. Abetz seinerseits konnte Hitler ein Kollaborationsangebot präsentieren, als er Ende Juli zu Konsultationen nach Salzburg fuhr. Im Sinne der mehrgleisigen Frankreichpolitik der Reichsregierung war das ein Erfolg, der seine Position in Paris festigte, abzulesen an der Ernennung zum Botschafter Anfang August ${ }^{26}$, der nominellen Aufwertung seiner Dienststelle zur "Botschaft“ im November ${ }^{27}$, als die Folgeverhandlungen des deutsch-französischen Gipfels von Montoire liefen, und der Übertragung umfänglicher Kompetenzen, zumindest auf dem Papier ${ }^{28}$. Fortan bildeten Abetz und Laval eine Zweckgemeinschaft, in der jeder den anderen brauchte, um den Kurs des Nachbarlandes an den eigenen Zielen auszurichten. Bald jedoch stellte sich heraus, daß beide ohne Rückhalt ihrer Regierungen zu Werke gingen.

\section{Verlogene Geschäftsgrundlage: Die deutschen Kollaborationsperspektiven}

Im Sommer 1940 habe Hitler Berichterstattern noch Zeit eingeräumt, persönliche Ansichten auszubreiten, erzählte Abetz. Bei einer Audienz am 3. August auf dem Berghof erläuterte er dem ,Führer', wie wichtig es für eine künftige deutsch-französische Entente sei, eilends einen Vernunftfrieden zu schließen und im Vorgriff darauf das Besatzungsregime zu lockern. Seine Vorschläge stießen jedoch ins Leere. Hitler schwadronierte über die Schönheit von Paris und Frankreichs Rang

25 Exemplarisch ein Vorstoß von Innenminister Adrien Marquet, der der SS über seinen Kabinettschef Coustau mitteilte, er stehe "für eine ehrliche Annäherung “ bereit. Die aktuelle französische Regierung - einschließlich Laval - sei dazu ungeeignet. Heydrich an Ribbentrop, 27. 7. 1940, mit einem Protokoll der Unterredung zwischen Coustau und SD-Vertretern vom Vortag; ADAP, D X, Nr. 247. Im August sprachen unter anderem Bonnet und Flandin in der Rue de Lille vor.

26 Der Reichsaußenminister an den Chef des Oberkommandos der Wehrmacht, 3. 8. 1940, ebenda, Nr. 282. Die Ernennungsurkunde datiert vom 15. August. Ein Vermerk auf der Rückseite besagt: ${ }_{n}$ Es handelt sich um die Besetzung der Stelle Nr. 8, die durch Versetzung des Botschafters Graf Welczeck in den Wartestand frei geworden ist." PA/AA, Personalakte Abetz/3.

27 Führerentscheid vom 20. 11. 1940; ADAP, D XI.2, Nr. 368.

28 Ribbentrop an Keitel, wie Anm. 26. Abetz sollte ständigen Kontakt mit der Vichy-Regierung halten, auf maßgebliche französische Persönlichkeiten einwirken, Kunstschätze sicherstellen, Presse, Rundfunk und Propaganda "politisch leiten“ und militärische Stellen beraten, desgleichen GFP und Gestapo bei der Beschlagnahme wichtiger Dokumente. "Ausdrücklich“ wurde angeordnet, daß er „ausschließlich [...] für die Behandlung aller politischen Fragen im besetzten und unbesetzten Frankreich verantwortlich" sei. Dietrich, Auseinandersetzung, S. 42/62, wertet die Ernennung zum Botschafter als Indiz für eine gewachsene Bedeutung Frankreichs im strategischen Kalkül der Reichsführung und als ein Resultat Ribbentropscher Bemühungen, über Waffenstillstandskommission und Militärbefehlshaber hinweg Einfluß auf das deutsch-französische Verhältnis zu nehmen und das Konzept eines "Kontinentalblocks“ zu beleben. 
in der europäischen Völkerfamilie, vermied es aber, sich politisch festzulegen. Solange der Kampf gegen England andauere, hätten militärische Interessen Priorität. Die Demarkationslinie müsse wegen Spionagegefahr abgeriegelt bleiben, Kriegsgefangene könnten nur in Einzelfällen freigelassen werden, weil sie als Arbeitskräfte in Deutschland benötigt würden. Erst nach der Niederwerfung Englands sei er zu Gesprächen mit den Franzosen bereit, von deren „praktischem Verhalten" ein großzügiger Frieden abhänge. Am Ende war Abetz, wie er in seinen Memoiren bekennt, "nicht viel klüger als zuvor". Er tröstete sich damit, daß Hitlers Aussagen „nichts im negativen Sinn“ präjudizierten, fragte sich aber, inwieweit die besiegten Nachbarn zu einer prodeutschen Neuorientierung bereit wären, wenn man sie im ungewissen über die Friedensbedingungen ließ. „Das Pferd schien mir am Schwanze aufgezäumt zu sein." Zudem habe die Reichsregierung die Wechselwirkung von Politik und Kriegführung unterschätzt: „Selbstverständlich mußten die Aufrechterhaltung der öffentlichen Ruhe und Ordnung im besetzten Gebiet und die Verhinderung eines Fußfassens der Engländer in Französisch-Nordafrika allen anderen Interessen vorangehen. Beides war aber um so sicherer gewährleistet, je schneller die politischen Fragen zwischen Deutschland und Frankreich befriedigend gelöst wurden. ${ }^{2} 29$

Viel zu einseitig und wankelmütig war indessen Hitlers Kollaborationsperspektive, als daß etwas Tragfähiges daraus erwachsen konnte. „Zusammenarbeit" nach Berliner Spielregeln ging kategorisch zu Lasten der Franzosen, die sich vage in Aussicht gestellte Vergünstigungen durch Vorleistungen erkaufen sollten - eine verlogene Geschäftsgrundlage, wie nicht nur Goebbels und Göring freimütig einräumten ${ }^{30}$. Hinzu kam, daß Hitler unverändert in Erbfeind-Kategorien dachte und Frankreich notorisch mißtraute ${ }^{31}$. In seinem Kalkül war das Land stets eine von den unmittelbaren Bedürfnissen des Reiches abhängige Größe. Allenfalls vorübergehend wuchs im Sommer 1940 seine Verhandlungsbereitschaft, als das erwartete Einlenken der Briten ausblieb und nach zusätzlichen Druckmitteln gesucht wurde, sie gefügig zu machen. Zur Debatte stand eine militärische Kooperation mit dem Vichy-Regime im Mittelmeerraum, die angesichts der vernichtenden

${ }^{29}$ Abetz, Das offene Problem, S. 141 ff. Vgl. Verhörprotokoll Nr. 204/10 vom 22. 11. 1945, „Exposé des directives données par Hitler à Abetz et l'organisation de l'Ambassade du Reich à Paris“; AN, F 7/15331, ein weiteres Exemplar CDJC, LXXI-114.

30 Charakteristisch für den damaligen Sprachgebrauch eine Notiz Halders vom 4. 11. 1940: Frankreich mochte „in dem Maße geholfen werden, in dern es etwas für uns leistet". Kriegstagebuch, II, S. 165. Gänzlich unverbrämt dagegen Göring bei einer Konferenz mit den Reichskommissaren und Vertretern der Militärbefehlshaber für die besetzten Gebiete im August 1942: „Kollaboration der Herren Franzosen sehe ich nur in folgendem: wenn sie liefern, bis sie selber nicht mehr können." IMT, Bd. 39, S. 391. Desgleichen Goebbels: "Das Gerede von Kollaboration ist nur für den Augenblick gedacht." Tagebücher 1942/ 43, S. 177 (Eintrag vom 26. 4. 1942).

31 Ein Beleg unter vielen seine Aussage gegenüber Abetz am 5. 1. 1942, „daß er sich unter ,Collaboration" nichts Substantielles vorstellen könne“. Die Franzosen verständen darunter, „daß wir ihnen allerhand geben müßten, ohne daß sie zu konkreten Gegenleistungen bereit wären“. Abetz, „Die deutsch-französischen Beziehungen seit dem Waffenstillstand“, Denkschrift vom Juli 1943 [Abetz-Memorandum 1943], pag. 165 f.; abgedruckt ADAP, E 1, S. 558. 
Bombardierung französischer Kriegsschiffe durch englische Flottenverbände am 3. Juli im algerischen Hafen Mers el-Kebir und des britisch-gaullistischen Vordringens in Französisch-Afrika phasenweise greifbar nahe schien, jedoch von beiderseitigen Vorbehalten, italienischen und spanischen Ansprüchen, Hitlers eigener Maßlosigkeit, seiner Fixierung auf einen deutsch-englischen Kompromiß und der anlaufenden Planung für den Ostfeldzug überlagert war ${ }^{32}$. Das hieraus resultierende Lavieren der Reichsführung zwischen strategischen und bündnispolitischen Alternativen bedingte eine schwankende, im letzten immer nur taktisch bedingte Haltung gegenüber Frankreich, die nach Abetz' Einschätzung einen durchaus möglichen "Wechsel der Allianzen" vereitelte: "Jeder Teilnehmer des Westfeldzuges bestätigt, daß es nach dem Waffenstillstand ein leichtes gewesen wäre, das französische Volk zu einem Krieg gegen England zu bewegen [... ] Diese Stimmung hielt nicht lange an. Das Ausbleiben der deutschen Invasion in England konnte Hoffnungen auf einen Wechsel des Kriegsglücks erwecken. Die Überstellung der französischen Kriegsgefangenen nach Lagern in Deutschland, die Zerschlagung vieler mit deutschen Kriegsinteressen nichtkollidierender französischer Produktionszweige, der [...] völlig veränderte Ton der deutschen Presse und des deutschen Rundfunks und die Ausgliederung der Norddepartements und der Sperrzone [...] ließen die Franzosen erkennen, daß der Krieg gegen ,England', ungeachtet der Versicherungen der deutschen Propaganda, auch sehr wohl ein Krieg gegen ,Frankreich" war." 33 Licht auf die divergierenden Vorstellungen in der Umgebung des ,Führers' und der Rue de Lille, wie mit dem besiegten Land zu verfahren sei, wirft das Zeugnis Kurt Georg Kiesingers, der im Juli 1940 als Mitarbeiter der AA-Rundfunkabteilung in Paris weilte und mit Abetz ins Gespräch kam: „Ich gewann den Eindruck, daß auch ihm ein rascher versöhnender Friedensschluß äußerst erwünscht schien. Aber in Berlin, sagte er voller Zorn, habe man ganz andere Pläne. ,Dort sitzen die schlimmeren Gaullisten" “"34

Durch „die Macht der Tatsachen“ wollte Abetz deshalb Hitler „von der Möglichkeit einer Verständigung" überzeugen ${ }^{35}$. Weil aber der deutsche Herrschaftsanspruch auch in seinem Konzept eine Konstante war, die aufrichtiger Partnerschaft zuwiderlief, mündete dieses Unterfangen in eine „doppelte Manipulation"36: Während Hitler seinem Botschafter nie ganz die Hoffnung nahm, daß eine großzügige Übereinkunft mit den Franzosen möglich sei, sofern sie sich einer solchen als würdig erwiesen ${ }^{37}$, tatsächlich aber in unversöhnlichem $\mathrm{Haß}$ verharrte,

32 Eine ausführliche Analyse der politischen und militärischen Optionen Deutschlands 1940 und der Rolle, die Frankreich in den Planspielen zukam, bei Hillgruber, Strategie, Kap. IIIV; Dietrich, Auseinandersetzung, Kap. II und III; Geschke, Deutsche Frankreichpolitik 1940; Queuille, La politique d'Hitler à l'égard de Vichy, S. 256-267.

33 Abetz-Memorandum 1943, pag. 3 f.

34 Kiesinger, Dunkle und helle Jahre, S. 223.

35 Abetz, Das offene Problem, S. 143.

36 Burrin, La France, S. 103 f.

37 Am 16. 9. 1941 sagte Hitler seinem Botschafter, die Franzosen seien ein anständiges Volk; sie sollten am ,neuen Europa teilhaben und würden gewiß eine große Blüte erleben. „Voraussetzung freilich sei, daß die Franzosen vernünftig genug wären, sich rückhaltlos in die ,neue Ordnung' einzupassen, und alle Koalitionsgedanken aufgäben." Unsig. Aufzeichnung; ADAP, D XIII.2, Nr. 327. 
nährte und instrumentalisierte Abetz das Verlangen kollaborationswilliger Zirkel, Partner unter einem europäischen Dach zu werden, wiewohl sein Denken geradezu programmatisch auf die Bildung eines gespaltenen, politisch ohnmächtigen „Vasallenstaates" 38 zielte. Konturen gewann diese abgründige Version eines Friedens am Rhein in der mehrfach zitierten Denkschrift, die Abetz Ende Juli 1940 vor seiner Audienz bei Hitler verfaßt hatte. Sie kreist um die Frage, wie ein politisch geschlossenes Frankreich, das "ein dauernder Intrigenherd gegen das Reich [wäre]", zu verhindern sei. Die Antwort degradiert selbst den bevorzugten Unterhändler Laval zum nützlichen Statisten. Entscheidend sei, daß mit verteilten Rollen gespielt werde. Dabei müßten „die Härtegrade unserer Haltung je nach Partner und dem ihm zugedachten Zweck variieren. Ein Teil der politischen Persönlichkeiten und Bewegungen muß in der Hoffnung beziehungsweise Illusion einer späteren Verständigungsmöglichkeit mit Deutschland belassen werden. " Mehr als ein "gewisses Eingehen“ auf die von Laval, Déat und anderen geplante Einheitspartei schien unter solchen Vorzeichen kaum opportun, wohl aber zeitige Einflußnahme auf die Berufsstände der Bauern, Handwerker und Arbeiter, da sich Frankreich zu einem korporativen Staat entwickle, die Förderung regionalistischer Tendenzen, die vorbeugende Bekämpfung des Kommunismus und ein erträgliches Leben für das Millionenheer der Kriegsgefangenen, die bei schlechter Behandlung „für Lebzeiten Träger einer gegen das Reich gerichteten Hetze mit entsprechender Massenwirkung werden ". Darüber hinaus galt es englandfeindliche Stimmungen zu schüren, ein "Gefühl für die Schicksalsgemeinschaft des Kontinents" zu wecken, der Bourgeoisie als "Trägerin des französischen Staatsgefühls" die wirtschaftlichen Ressourcen zu entwinden und Bedingungen für die Werktätigen zu schaffen, ,welche ihnen die Einbeziehung in den [...] Lebensraum des deutschen Volkes als materiell vorteilhaft erscheinen lassen“. Auch sei anzuraten, „unsere Militärgrenze bis zum Atlantik vorzutragen, das heißt, das gesamte Frankreich für dauernd unter unseren Schutz zu nehmen" 39 .

Überlegungen zur künftigen deutschen „Westpolitik“ hatte Abetz bereits Ende Mai in einem Schreiben an das Oberkommando der Wehrmacht angestellt. Damals befürwortete er eine Zusammenarbeit mit politischen Zirkeln, die dem Nationalsozialismus naheständen, und eine Propaganda, die den besiegten Völkern die Schwäche ihrer bisherigen Regierungen vor Augen führen und die Vorzüge des ,Dritten Reichs' etwa auf sozialem Gebiet herausstellen sollte ${ }^{40}$. Das im Tonfall wie in der Handlungsanleitung wesentlich aggressivere ,Salzburg-Memorandum' suchte er vor Gericht als Täuschungsmanöver abzutun; es habe ihn, den "von allen Seiten belauerten“ diplomatischen Neuling, im Urteil der Parteioberen als verläßlichen Gefolgsmann ausweisen sollen: „Je voulais paraitre le dur des durs." In Wahrheit habe die Botschaft Paris einen "diametral entgegengesetzten“

38 Abetz, „Lagebericht für den Herrn Reichsaußenminister. Frankreich ein Jahr nach dem Waffenstillstand“", 23. 6.1941; MAE, Papiers 1940, Papiers Abetz/2.

39 Abetz, "Politische Arbeit in Frankreich“, Salzburg, 30. 7. 1940; CDJC, LXXI-28.

40 Abetz (Referat West der Dienststelle Ribbentrop) an OKW/Wehrmachtführungsamt, 24. 5. 1940, zitiert bei Umbreit, Der Kampf um die Vormachtstellung in Westeuropa, in: Deutsches Reich und Zweiter Weltkrieg, 2, S. 324. 
Kurs verfolgt ${ }^{41}$. Erst auf hartnäckiges Fragen des Vorsitzenden Richters räumte der Angeklagte ein, manche Vorschläge hätten durchaus seiner Überzeugung entsprochen, so die Empfehlung, innerfranzösische Meinungsverschiedenheiten zu vertiefen - das sei eine ebenso gebräuchliche wie moderate Methode des Siegers, den Unterlegenen niederzuhalten ${ }^{42}$. Wie ernst es ihm damit war, dokumentiert ein Gespräch mit Werner Best am 17. August 1940, wenige Tage nach der Ernennung zum Botschafter. Als „maßgebende Richtlinie der Reichspolitik“ nannte Abetz hier ein schwaches Frankreich ohne Verbindungen zu deutschfeindlichen Mächten. „Deshalb besteht kein Interesse einer Unterstützung wirklich völkischer oder nationaler Kräfte [...] Zu unterstützen sind vielmehr jeweils diejenigen Kräfte, die erforderlich sind, um die Uneinigkeit zu fördern; das können einmal links gerichtete und ein andermal rechts gerichtete Kräfte sein." Selbst den Kommunisten war ein beschränkter Part in diesem Ränkespiel zugedacht ${ }^{43}$. Doch war Abetz früh bestrebt, ihren Einfluß in der Arbeiterschaft einzudämmen, wie Ende September formulierte Pläne belegen. Darin ermunterte er den Militärbefehlshaber, im besetzten Gebiet Syndikate zuzulassen; für ihre Leitung habe sein Stab „unseren Gedankengängen nahestehende französische Gewerkschaftsführer verschiedenster Richtung" an der Hand. Forderungen an die Arbeitgeber müßten im voraus mit den deutschen Stellen abgestimmt werden, die Militärverwaltung als oberste Schiedsbehörde fungieren. Es folgten detaillierte Vorschläge für „wirtschaftliche Sofortmaßnahmen", die Abetz propagandistisch ausschlachten wollte. Löhne und Preise sollten so gestaltet werden, daß die Lebenshaltungskosten stabil blieben, Arbeitslose mehr Unterstützung bekamen und im Gegenzug an Projekten zur Verbesserung der Infrastruktur mitwirkten. Bedürftige sollten von kulturellen Gratisangeboten und einem Winterhilfswerk profitieren, das teilweise aus dem „Erlös des von Juden und sonstigen Kriegsschuldigen beschlagnahmten Eigentums" zu finanzieren sei ${ }^{44}$.

Exemplarisch zeigt sich das Bemühen, Einfluß auf breite Bevölkerungsschichten zu gewinnen, sie durch Vermeiden unnötiger Härten ruhigzustellen und die politischen Strömungen im Land zu neutralisieren. Sympathie für die Franzosen und die Hoffnung, daß gewieftes Taktieren sie eng an die Hegemonialmacht Deutschland binden werde, ließen Abetz dabei meist moderater, manchmal allerdings auch bewußt schärfer argumentieren als Vertreter anderer Reichsorgane der Zweck heiligte die Mittel. Doch verstand er sich trotz reger eigener Vorstellungen, wie das Verhältnis zwischen Siegern und Besiegten beschaffen sein sollte, stets als Sachwalter deutscher Kriegführung, auch dann, wenn er in seinen Augen schädliche Bestrebungen im eigenen Lager konterkarierte und sich dem Vorwurf ungebührlicher Frankophilie aussetzte. Die Folgen seines Wirkens mögen nicht immer die letzten Absichten spiegeln, wiegen aber gleichwohl schwer: Sein Vorpreschen in der Judenfrage arbeitete nackter Gewalt vor, sein Werben um Kolla-

41 Abetz-Prozeß, 13. 7. 1949, pag. 1 ff.; AN, 334 AP 49.

42 Ebenda, pag. $18 \mathrm{ff}$.

43 Vermerk Best vom 19. 8. 1940; AN, AJ 40/539.

44 Abetz, , Vorschlag zu einer Neuordnung des Gewerkschaftswesens und zu sozialistischen Maßnahmen im besetzten Frankreich“, 26. 9. 1940; PA/AA, R 27355. 
boration begünstigte die Ausbeutung französischer Ressourcen, seine Propaganda ging einher mit Bevormundung und Zensur. Daß er die üblichen Drohgebärden und Repressalien des NS-Regimes durch verführerische Elemente gleichsam ergänzte, in der Kulturpolitik und als selbsterklärter Exponent des Ausgleichs, steigerte nur die Wirkung - wie schon vor dem Krieg.

\section{Einrücken in die Kontinentalfront? Der Weg nach Montoire}

Kaum war Abetz Ende der ersten Augustwoche 1940 wieder in Paris, sprach Pierre Laval erneut bei ihm vor. Er erhoffte sich Lockerungen des Besatzungsregimes, um der wachsenden Kritik im Kabinett an seiner Person begegnen zu können. „Es arbeiten zwei Gruppen gegen ihn“, setzte Brinon die Deutsche Botschaft ins Bild: eine pro-englische unter Führung Baudouins sowie ein Kreis um Weygand, Ybarnegaray und La Rocque, der Lavals Avancen für unvereinbar mit der nationalen Würde halte ${ }^{45}$. Nachdem Pétain Mitte Juli Hilfsleistungen für die deutsche Luftwaffe und Kriegsmarine im Mittelmeerraum abgelehnt hatte, geriet Frankreich zusehends fester in den Würgegriff der Besatzungsmacht, die die Bestimmungen des Waffenstillstandsvertrags vielfach ignorierte. Lothringen und das Elsaß wurden de facto annektiert, Personen-, Güter- und Postverkehr über die Demarkationslinie erschwert. Am 8. August bezifferte die Reichsregierung die von Frankreich zu zahlenden Besatzungskosten auf 400 Millionen Francs täglich - ein bodenloser Betrag. Diese und andere Fesseln drohten das Wirtschaftsleben vollends zu strangulieren, nationalsozialistischer Willkür schienen Tür und Tor geöffnet ${ }^{46}$. Die Deutschen ließen es allenthalben an Zusammenarbeit und Toleranz fehlen, zürnte ein Memorandenschreiber in Vichy und beklagte im besonderen die politische und administrative Teilung des Landes ${ }^{47}$.

So nimmt es nicht wunder, daß Laval regelrecht um ein Zugeständnis flehte, als er am 9. und 10. August in der Rue de Lille empfangen wurde. Noch war er seinen Rivalen jeden Beleg schuldig geblieben, daß sein Kurs Frankreichs Los erleichtern werde; doch hatte er in Vichy darauf gedrungen, Abetz' Rückkehr vom Berghof abzuwarten ${ }^{48}$. Nun bat er um Erlaubnis, die französische Regierung nach Paris zurückverlegen zu dürfen, wenigstens aber - „um ein kleines Ergebnis seiner $\mathrm{Be}$ sprechungen nachweisen zu können" - die Ministerien für Verkehr, Finanzen, Landwirtschaft und Arbeit ${ }^{49}$. Er unterstützte damit das dringliche Anliegen Pétains, in Paris oder Versailles zu residieren. Der Marschall wollte dadurch seine

45 Schleier für Abetz, 2. 8. 1940; PA/AA, R 29587. Admiral Darlan hat die Spannungen dokumentiert: „Evénements“, 2. August, in: Lettres et notes, S. 195. Ausführliche Fassung bei Coutau-Bégarie/Huan, Darlan, S. 338.

46 Einzelheiten bei Jäckel, Frankreich, S. 80 ff., 90 ff.; Geschke, Frankreichpolitik, S. 42 ff., $51 \mathrm{ff}$.; Aron, Histoire de Vichy, S. $267 \mathrm{f} ., 274 \mathrm{ff}$.

47 „Rapports franco-allemands“, unsig., 14. 8. 1940; MAE, Vichy-Europe, Série Y, Bd. 289.

48 Cointet, Laval, S. 284.

49 Abetz an Ribbentrop, 10. 8. 1940; PA/AA, R 29587. 
Autorität auch in der besetzten Zone behaupten, eine möglichst einheitliche Verwaltung gewährleisten und opponierenden Pariser Presseorganen Paroli bieten; $\mathrm{da} ß$ sie mit Duldung deutscher Zensoren organisatorische und politische Fehler seines Regimes anprangerten, mochte schlimmstenfalls die Bildung einer den $\mathrm{Be}-$ satzern ergebenen Gegenregierung fördern ${ }^{50}$. Doch obschon es der französischen Führung im Waffenstillstandsvertrag freigestellt worden war, in die Metropole zu ziehen, stieß ihr Wunsch seither auf taube Ohren. Hitler verfügte, die Angelegenheit zu verschleppen, nicht zuletzt aus dem propagandistischen Kalkül, das Kabinett Pétain im In- und Ausland als vergleichsweise unabhängig erscheinen zu lassen, indem er es auf Distanz hielt ${ }^{51}$.

Sichtlich bemüht, Laval einen Erfolg zu verschaffen, befürwortete Abetz demgegenüber die Rückkehr von vier Ministerien nach Paris. Er betonte die "Notwendigkeit“, den stellvertretenden Ministerpräsidenten zu stützen. Darüber hinaus entlaste ein Teilumzug der französischen Regierung die deutsche Kriegsverwaltung und ermögliche es, unmittelbar auf die in Arbeiter- und Bauernschaft einflußreichen Minister Belin und Caziot einzuwirken. Belange der Abwehr würden nicht berührt, „da technisches Personal genannter Ministerien schon in Paris tätig “52. Ribbentrop indes beschied seinen Botschafter, er möge derlei Themen weiter dilatorisch behandeln: „Eine solche Übersiedlung kommt derzeit nicht in Frage, da Paris und Nordfrankreich Operationsgebiete gegen England sind." 53 Abetz sah sich gezwungen, abzuwinken und darauf hinzuweisen, daß die jüngsten Erschwernisse im Post- und Personenverkehr „den gleichen Erwägungen entspringen“. Allerdings werde ein Übergang eigens für Regierungsmitglieder und Politiker geschaffen, um ihnen den Zonen-Transfer zu erleichtern. Ein Passierschein für Lavals persönlichen Gebrauch lag dem Schreiben bei. Und als wollte er dem kollaborationswilligen Franzosen anderweitige Möglichkeiten aufzeigen, skizzierte Abetz Pläne für eine Rückkehr der Agence Havas nach Paris, wo Redakteure beider Länder das Nachrichtenmaterial aufbereiten sollten ${ }^{54}$.

Das Bemühen, den Auvergnaten trotz des damaligen Tiefpunkts im deutschfranzösischen Verhältnis im Sattel zu halten, läßt sich im übrigen einem von Abetz inspirierten Bericht Luchaires für Pétain vom 22. August entnehmen. „La loyauté, le patriotisme et la haute intelligence de M. Pierre Laval nous inspirent une confiance totale", ließ der Botschafter über seinen Duzfreund verlauten, nicht ohne warnend anzufügen: „Mais nous doutons maintenant que M. Laval puisse vaincre,

50 Hierzu und zum Folgenden Jäckel, Frankreich, S. 86 ff.; Geschke, Frankreichpolitik, S. $57 \mathrm{ff}$; Delpla, Montoire, S. $121 \mathrm{ff}$.

51 Aufzeichnung v. Grote, 11.7. 1940; PA/AA, R 29607. Aufzeichnung Schmidt über die Unterredung Hitler-Darlan am 24. 12. 1940; ADAP, D XI.2, S. 793. Vgl. Artikel 3 des Waffenstillstandsvertrags, abgedruckt ebenda, D IX, S. 555.

52 Abetz an Ribbentrop, wie Anm. 49.

53 Antwortschreiben vom 16. 8. 1940; ADAP, D X, Nr. 351.

54 Abetz an Laval, 19. August; MAE, Papiers 1940, Papiers Laval/2. Zum Schicksal der Agentur Havas siehe Histoire générale de la presse française, IV, S. $26 \mathrm{f}$.; Dioudonnat, L'argent nazi, S. $89 \mathrm{ff}$. 
à Vichy, les obstacles qui s'opposent à sa politique. " 55 Der Belobigte wartete unterdessen weiter auf ein Zeichen deutscher Verhandlungsbereitschaft, obwohl ihm Abetz zuletzt ziemlich zugeknöpft begegnet war $^{56}$. „De bonnes paroles mais rien de précis“, kommentierte Darlan die zweite Audienz des Kabinettskollegen in der Rue de Lille ${ }^{57}$. Bereits Ende August aber weilte Laval erneut in Paris. Diesmal führte Abetz seinen Gast bei den Spitzen des deutschen Militärapparats, Brauchitsch und Streccius, ein ${ }^{58}$. Es wurden gewisse Erleichterungen im Postverkehr über die Demarkationslinie vereinbart, so die Einführung von Briefkarten, die in vorgedruckten Sätzen über das Befinden von Familienangehörigen informierten. Außerdem solite täglich ein Kurier zwischen Paris und Vichy pendeln und das Journal officiel auch in der Hauptstadt verteilt werden ${ }^{59}$.

Tiefen Einblick in Lavals Werben um die Gunst der Deutschen gibt ein Protokoll des Abetz-Vertrauten Friedrich Grimm, der Laval am 28. August bei einem befreundeten Rechtsanwalt traf. Während des gut zweistündigen Gesprächs bekannte sich der stellvertretende Ministerpräsident vorbehaltlos zu einer umfassenden Zusammenarbeit mit dem Reich. Zugleich äußerte er Verständnis, daß das künftige Miteinander erst nach Beendigung des Englandkrieges an Kontur gewinnen könne. Er glaube indes felsenfest, daß England - „unser gemeinsamer Feind“ - verloren sei. Daran knüpfte Laval ungeniert die Hoffnung, sein Land werde für eigene Gebietsverluste aus britischem Kolonialbesitz in Afrika entschädigt; das Elsaß hatte er bereits abgeschrieben. Gegen eine Neuordnung Europas unter deutscher Führung und eine wirtschaftliche Durchdringung Frankreichs habe man "nichts einzuwenden". Grimms Einwurf, die gegenseitigen Beziehungen bedürften auch einer neuen weltanschaulichen Grundlage, pflichtete Laval ohne Zögern bei: „Wir haben erkannt, welche Rolle die Juden als Kriegshetzer gespielt haben, und wir sind entschlossen, die Judenfrage in Eurem Sinn zu lösen."60

$\mathrm{Da}$ es Vichy im letzten Punkt keineswegs bei Drohgebärden beließ, dokumentiert die Welle judenfeindlicher Dekrete im Sommer und Herbst 194061. Aber auch die übrigen Aussagen Lavals passen wie sorgsam ausgestanzte Puzzle-Teile in das politisch-ideologische Gedankengebäude der Deutschen Botschaft, wo ihm eine Reputation erwuchs, die alle taktischen Manöver und historischen Wechselfälle überdauerte. „Laval wird nach wie vor von Deutschland in jeder Beziehung gedeckt und ist [...] der alleinige Garant einer wirklichen Collaboration", gaben Gustav Feihl und Rudolf Rahn Ende Januar 1941, nach dessen Sturz, vor Presse-

55 Luchaire an Pétain, 22. 8. 1940, zit. in einem Bericht der Zeitung Paris-Presse vom 31. 10. 1945; AN, AJ 72/465.

56 So das Zeugnis Lavals vom 10. August, zit. von Baudouin, Neuf mois, S. 287.

57 "Evénements“, 10. August, in: Lettres et notes, S. 195.

58 Abetz an Auswärtiges Amt, 30. 8. 1940; ADAP, D X, Nr. 411.

59 Abetz an Stülpnagel (Wiesbaden), 29. August; MAE, Papiers 1940, Papiers Laval/2.

60 Grimm, „Besprechung mit Ministerpräsident Pierre Laval im Hause von Marcel Ribardière am 28. August 1940" (13 S.); PA/AA, Botschaft Paris 1270. Der Abdruck in Grimm, Frankreich-Berichte, S. 144ff., entspricht bei weitem nicht der zitierten Fassung aus den Akten. Im besonderen fehlt die Passage zur "Regelung des Judenproblems“.

61 Siehe Kap. X. 
offizieren als propagandistische Leitlinie aus ${ }^{62}$. Abetz bekannte, neben den fortgesetzten engen Beziehungen zu Laval sei der Umgang mit anderen französischen Ministern zweitrangig („d'importance secondaire“) gewesen ${ }^{63}$. Presseattaché Feihl attestierte seinem Chef, er habe Lavals Feinde als die eigenen betrachtet ${ }^{64}$. Ein nuancierteres Bild zeichnete Rudolf Schleier. Er betont, daß der Franzose mitnichten nur Erfüllungsgehilfe deutscher Besatzungspolitik gewesen sei: „Es ist nur wenigen Außenstehenden deutlich geworden, mit welcher Zähigkeit und Hartnäckigkeit er immer wieder seinen persönlichen Standpunkt vertrat [...] und in kluger Argumentation die politische Schädlichkeit [deutscher] Forderungen nachwies. "65 Das war gewiß auch in der Absicht geschrieben, einen weithin Geächteten zu rehabilitieren. In jedem Fall aber ist Laval gleich mehreren Irrtümern aufgesessen: Er täuschte sich über Englands Durchhaltevermögen und überschätzte den Kollaborationswillen der Reichsregierung ebenso wie Abetz' Einfluß bei Hitler ${ }^{66}$. Die ersehnte Rolle des starken Mannes in Vichy war so nicht zu erlangen.

Zunächst freilich bahnte sich eine Entwicklung an, die ungeahnte Chancen für ein Zusammengehen zu eröffnen schien. Englands ungebrochene Gegenwehr, die Verschiebung der Operation "Seelöwe" auf unbestimmte Zeit und der alarmierende Vormarsch britisch-gaullistischer Truppen in Französisch-Afrika weckten im September 1940 Hitlers Interesse an einer militärischen Kooperation mit Franco und Pétain. Diese Erwägungen, von Beratern wie Raeder und Stülpnagel bestärkt, liefen auf Ribbentrops Idee eines „Kontinentalblocks“ hinaus. Hitler selbst bezeichnete eine „europäische Koalition gegen England unter Einschluß Frankreichs und Spaniens" nunmehr als „Ideallösung“, wenigstens „im Augenblick "67. Durch gemeinsame Aktionen, die Eroberung Gibraltars und die Errichtung deutscher Operationsbasen in Nordafrika sollten die Briten aus dem westlichen Mittelmeer und dem französischen Empire vertrieben und die europäische Südflanke gesichert werden. Allerdings mußte der ,Führer' rivalisierende Ansprüche unter einen Hut bringen, wollte er ein solches Bündnis schmieden - eine schwierige Hürde, die er mit einem „grandiosen Betrug “ 68 zu meistern gedachte. Am 4. Oktober erläuterte er dem ,Achsen'-Partner Mussolini seinen Plan: Italien sollte bei Kriegsende Nizza, Korsika und Tunis erhalten, Franco seine Wünsche zurückschrauben, Frankreich zwar den marokkanischen Besitz an Spanien abtreten, dafür aber in Britisch-Nigeria entschädigt werden. Das waren lauter ungedeckte Wechsel, von den Forderungen des Reiches ganz zu schweigen. Gleichwohl hoffte Hitler, die Franzosen würden trotz aller Vagheiten mitziehen ${ }^{69}$.

62 „Tätigkeitsbericht der Propaganda-Abteilung Frankreich für die Zeit vom 26. 1.-2. 2. $1941^{\circ}$, pag. 2; AN, AJ 40/1001.

63 Verhörprotokoll Nr. 204/33 der Sûreté Nationale vom 18. 11. 1945; AN, F 7/15331.

64 Protokoll Nr. 149/4 der Sûreté vom 1. 9. 1946; AN, 3 W 358, Dossier Feihl.

65 "Pierre Laval“; PA/AA, Nachl. Schleier/IV.2.

66 Vgl. die Analyse von Michel, Vichy, année 40, S. 277.

67 Aufzeichnung Schmidt über die Unterredung Hitler-Mussolini auf dem Brenner am 4. 10. 1940; ADAP, D XI.1, S. 216.

68 Überliefert von Halder, KTB, II, S. 124 (Eintrag vom 3. 10. 1940).

$69 \mathrm{Vgl}$. Aufzeichnung Schmidt. Zum gewandelten politisch-strategischen Konzept der 
Mehrere Faktoren förderten damals den Gedanken einer Revision der deutschen Frankreichpolitik. Die Spanier zauderten und schraubten den Preis für ein aktives Eingreifen ins Kriegsgeschehen so hoch, daß der ,Führer' schließlich verärgert auf Alternativen sann ${ }^{70}$. Beeindruckt zeigte er sich anderseits von der entschlossenen Gegenwehr, die vichytreue Verbände beim britisch-gaullistischen Angriff auf die westafrikanische Seefeste Dakar leisteten; der Landungsversuch brach nach dreitägigen Gefechten am 25. September zusammen ${ }^{71}$. Damit hatte die Regierung Pétain hinlänglich bewiesen, daß sie willens und in der Lage war, ihr Territorium zu behaupten, sofern ausreichende militärische Mittel zur Verfügung standen. Erbost über die Attacke, ordnete sie Vergeltungsschläge gegen Gibraltar an und startete eine regelrechte Offensive mit dem Ziel, die Zusammenarbeit mit den Deutschen zu intensivieren. General Doyen drängte bei der Waffenstillstandskommission auf Verstärkung der französischen Luft- und Seestreitkräfte in Afrika. Er gelobte ihren loyalen Einsatz und forderte eine deutsche Garantie, daß erfolgreich verteidigte Gebiete bei Frankreich verblieben ${ }^{72}$. Doyens Adressat, General v. Stülpnagel, berichtete von „unverblümten Anspielungen“ auf ein Bündnis. Aus dem Führerhauptquartier verlautete, die Angelegenheit werde „sehr ernst geprüft"73.

Recht präzise Vorstellungen über die Grundlagen einer künftigen Kooperation entwickelte der neue Verteidigungsminister, General Huntziger, am 26. September bei einem von Abetz vermittelten Gespräch mit dem Oberbefehlshaber des Heeres v. Brauchitsch. Er betonte, es falle schwer, der englischen Propaganda zu begegnen, wonach die Franzosen ihre Kolonien letztlich doch an Deutschland oder Italien verlieren würden. Sein Land benötige deshalb einen „Hoffnungsschimmer" und Gewißheit über das Schicksal des Empire; der "nackten Tatsache“, daß Frankreich de facto „mit Deutschland gegen England“ kämpfe, müsse Rechnung getragen werden. Darüber hinaus wünschte Huntziger stärkere Einflußmöglichkeiten seiner Regierung in der besetzten Zone, namentlich auf die öffentliche Meinung und die Lebensmittelversorgung. Unter Hinweis auf die hohe Arbeitslosigkeit bot er an, die gesamte Industrie des Landes für die deutsche Rüstungsproduktion einzuspannen, wenn sie nur die notwendigen Rohstoffe erhalte ${ }^{74}$.

Ein weiterer Vorstoß erfolgte über den Beauftragten für die Kriegsgefangenen, Georges Scapini, der seine Mission in Berlin Ende September antrat. Gegenüber

Reichsführung im September/Oktober 1940, das an dieser Stelle nur summarisch behandelt werden kann, und seinen Rückwirkungen auf die deutsche Frankreichpolitik siehe Hillgruber, Strategie, S. 135 ff., 317 ff.; Jäckel, Frankreich, S. 103 ff.; Geschke, Frankreichpolitik, S. 67 ff.; Delpla, Montoire, S. 207 ff.; Hildebrand, Das vergangene Reich, S. 735 f., sowie Halder, Kriegstagebuch, Bd. II.

$70 \mathrm{Vgl}$. Hitlers Unmutsäußerungen gegenüber Ciano am 28. 9. 1940; ADAP, D XI.1, Nr. 124.

${ }^{71}$ Krautkrämer, Kriegswende, S. $45 \mathrm{ff}$.; Churchill, Second World War, II/2, Kap. XXIV.

72 Délégation française, I, S. $84 \mathrm{ff}$.

73 KTB Halder, II, S. 109 (23. 9. 1940).

74 Aufzeichnung vom 1. 10. 1940; ADAP, D XI.1, Nr. 112. Hinweis bei Halder, S. $114 \mathrm{f}$. Abetz erwähnt seine Vermittlung in einem „Politischen Lagebericht“ vom 8. Oktober; MAE, Papiers 1940, Papiers Abetz/2 (Abschr., 12 S.), in verkürzter Form auch enthalten im Abetz-Memorandum 1943, pag. 4-11. 
Vertretern des Auswärtigen Amts unterstrich er den Willen seiner Regierung zur Kooperation. Frankreich müsse ,jetzt in die Kontinentalfront einrücken“, in die es „von Natur aus“ gehöre. Voraussetzung dafür sei aber, daß man der Bevölkerung reinen Wein in Gebietsfragen einschenke und ihr Chancen eröffne, die heimische Wirtschaft wieder in Gang zu bringen. Auch bei der Freilassung von Gefangenen müßten die Deutschen guten Willen zeigen. Die politischen und ökonomischen Verhältnisse jenseits des Rheins schilderte Scapini „in trüben Farben“, wie ein Protokoll vermerkt. Zugleich warnte er vor Unruhen und wachsenden Antipathien gegen die Besatzungsmacht. Ihr Ansehen habe auch deshalb gelitten, weil die Propaganda der Militärs „das erklärende Moment“ für die aktuelle Lage vermissen lasse 75 .

Scapinis Vorsprachen reihen sich in die Kette französischer Offerten, eine Zusammenarbeit über den Waffenstillstandsvertrag hinaus zu begründen und damit einhergehend Konzessionen und politische Zusagen des Reiches zu erlangen. Ein Quellenvergleich zeigt, daß seine Argumente denen von Abetz und Laval auffallend gleichen - gut möglich, daß er in enger Abstimmung mit ihnen antichambrierte $^{76}$. Beide witterten Morgenluft und versuchten ihre Kollaborationspläne im Zeichen des Konflikts Vichy-London voranzutreiben. Eine Welle von Aufständen in Französisch-Äquatorialafrika, von Briten und Gaullisten geschürt, stärkte Ende August die prodeutschen Kräfte im Kabinett Pétain. Die Position Baudouins, der einen völligen Bruch mit Churchill vermeiden wollte, war nach den Worten des Generalsekretärs im Außenministerium Charles-Roux erschüttert, während Laval im Ministerrat offen die Frage einer Kriegserklärung an England stellte 77 . Die Regierungsumbildung am 6. September verschob die Gewichte - zumindest vordergründig - noch weiter in diese Richtung: Überwiegend „antiparlamentarisch, englandfeindlich und antisemitisch" präsentierte sich laut Abetz die neuformierte Ministerriege ${ }^{78}$. Zeitgleich häuften sich die Angebote, auf höchster Ebene über eine Neugestaltung der Beziehungen zu verhandeln. Fast täglich fuhren nun Abgesandte aus Vichy in der Rue de Lille vor. Colonel René Fonck, Flieger-As des ersten Weltkriegs, fragte im Namen Pétains, ob ein Treffen mit Hitler möglich sei. Finanzminister Bouthillier regte deutsche Rüstungsaufträge für Firmen im unbesetzten Gebiet an, Baudouin warb um die Freigabe zusätzlicher militärischer Mittel79. Über die letzte Visite erzählte Abetz seinem Intimus Brinon,

75 Aufzeichnungen Krug, 27. 9. 1940; v. Rintelen, 28. September; v. Weizsäcker, 30. September; PA/AA, R 29587.

76 Unterstaatssekretär Woermann hatte solches schon vorab vermutet. Aufzeichnung für den Reichsaußenminister, 25. 9. 1940; PA/AA, R 29877.

77 Aufzeichnung über die Ereignisse vom 27. bis 29. 8. 1940; MAE, Papiers 1940, Papiers Charles-Roux/2.

78 „Politischer Lagebericht“ vom 8. 10. 1940, wie Anm. 74. Daß das Stühlerücken keineswegs nur darauf zielte, den Deutschen entgegenzukommen, betont Krautkrämer, Entmachtung Lavals, S. 83 f. So verlor Innenminister Marquet sein Ressort an den Laval-Gegner Peyrouton und konnte Weygand als Generaldelegierter der französischen Regierung in Afrika künftig die Interessen der Achsenmächte weit wirkungsvoller unterlaufen.

79 Abetz, „Aufzeichnung über politische Besprechungen in der Zeit vom 6. bis 15. September 1940“; PA/AA, R 27355. Zur Unterredung mit Baudouin vgl. ADAP, D XI.1, Nr. 59. Ein weiteres Angebot, freiwillige wirtschaftliche Leistungen besatzungspolitisch zu ho- 
der Außenminister sei bestrebt gewesen, sich anstelle Lavals als Kontaktperson zu empfehlen, womit er freilich auf taube Ohren stieß. Der Botschafter würdigte in seiner Antwort Lavals Verdienste und meinte belehrend, hätte man auf diesen Mann gehört, wäre der Krieg vielleicht vermieden worden ${ }^{80}$.

Mit dem Kampf um Dakar schien ein "renversement des alliances“ näher zu rücken. Laval versicherte Abetz am 24. September, er wünsche und hoffe, daß sein Land einen „besonderen Anteil“ zur endgültigen Niederwerfung Englands beisteuern könne. So weit lehnte sich kein anderes Mitglied der Vichy-Regierung aus dem Fenster, obschon auch der stellvertretende Ministerpräsident darauf bestand, daß der westafrikanische Kolonialbesitz Frankreichs im künftigen Friedensvertrag unangetastet blieb ${ }^{81}$. Eine schnelle Klärung dieses Anliegens war kaum zu erwarten, insgesamt aber kam Bewegung in die deutsch-französischen Beziehungen. In den Ansichten des ,Führers' zeichne sich ein Wandel ab, heißt es im Kriegstagebuch des OKW für die letzte Septemberwoche: Sein Mißtrauen gegen die Franzosen sei nach den jüngsten Ereignissen dem Bestreben gewichen, sie „weitgehend vor unseren Wagen zu spannen“. Laut Auskunft der Reichskanzlei wollte Hitler zu diesem Zweck den persönlich geschätzten Ex-Botschafter François-Poncet und Marschall Pétain treffen ${ }^{82}$. General Jodl, Chef des Wehrmachtführungsstabs, eröffnete sogleich die Diskussion, "welche Form man einer gemeinsamen Kriegführung mit einem Hilfsvolk geben müsse“83. Halder urteilte nüchtern: „Die Entwicklung der Lage kann Frankreich als Bundesgenossen an unsere Seite führen und damit schwierige politische Probleme aufwerfen. "84

Otto Abetz zog in dieser Situation alle Register, um ein Umdenken in Berlin zu fördern. In seinem Bericht vom 8 . Oktober behauptete er, Lavals These, „daß die einzig mögliche französische Außenpolitik eine Zusammenarbeit mit Deutschland sei, selbst wenn die vom Reich bestimmten Friedensbedingungen sehr hart ausfallen", habe sich durchgesetzt. Die Regierung Pétain sei bereit, zumindest in Afrika ,in einen offenen Kriegszustand gegen England zu treten“. Bedingung sei „eine den Friedensvertrag präjudizierende Übereinkunft" zur künftigen Verteilung der Kolonialgebiete. Rhetorisch geschickt suchte der Botschafter Befürchtungen zu zerstreuen, die Verantwortlichen in Vichy könnten ein abgekartetes Spiel treiben und militärische Verstärkungen bei erster Gelegenheit gegen das Reich wenden. Für ihre Aufrichtigkeit spreche die Gewißheit, daß sie bei einem deutsch-englischen Kompromiß allein die Zeche bezahlen müßten, ein Sieg Englands aber selbst mit amerikanischer Hilfe nicht mehr denkbar sei. Um jedes Risiko auszuschalten, könnten die französischen Kräfte Seite an Seite mit deutschen

norieren, unterbreitete der Vorsitzende der französischen Wirtschaftsabordnung in Wiesbaden, de Boisanger; ebenda, Nr. 98.

80 Notizen Brinons vom 15. September; AN, 3 W 106, Dossier 2.8: „Colonies: Dakar, Liban, Syrie“.

81 Abetz an Auswärtiges Amt, 25. 9. 1940; ADAP, D XI.1, Nr. 102.

82 KTB OKW, I, S. $88 \mathrm{ff}$. (Einträge vom 24. und 26. 9. 1940).

83 Ebenda, S. 95 (28. September).

84 KTB Halder, S. 116f. (27. September). Ribbentrop hatte Mussolini noch am 19. September gesagt, Hitler sei „entschlossen, Frankreich nie mehr eine Rolle in der europäischen Politik spielen zu lassen“; ADAP, D XI.1, S. 104. 
oder italienischen Verbänden eingesetzt werden ${ }^{85}$. Besatzungspolitisch hielt Abetz es für angeraten, den Bogen der wirtschaftlichen Ausbeutung nicht zu überspannen. Massenarbeitslosigkeit und Lebensmittelrationierung hätten „stimmungsmäßig sehr nachteilige Folgen“, weil sie den Requisitionen der Siegermacht angelastet würden. Überdies drohe eine Ausbreitung des Kommunismus, sollte es dauerhaft an Beschäftigungsmöglichkeiten fehlen. Die Franzosen brächten durchaus Verständnis auf, wenn heimische Stahl- und Chemiewerke und andere mit deutschen Produktionsstätten konkurrierende Industriezweige vernichtet oder in ihrer Kapazität beschränkt würden. Doch wäre es schon aus propagandistischen Gründen sinnvoll, einen Ausgleich auf anderen Feldern wie Weinbau, Mode und Luxuswaren zu schaffen. Das war eine vielsagende Bemerkung im Hinblick auf die Komparsenrolle, die Abetz den linksrheinischen Nachbarn bei allem vordergründigen Entgegenkommen zudachte. Seine Strategie, sie mit einem ausgeklügelten System der Einflußnahme zu kontrollieren, tritt auch in diesem Dokument hervor. So befürwortete er aus psychologischen und ökonomischen Gründen eine Lockerung der Demarkationslinie, nicht ohne zu betonen, daß ein „systematisches Wachhalten“ oppositioneller Kräfte als Druckmittel gegen Vichy tauge. Als "schwächsten Punkt" der französischen Regierung erkannte er ihre fehlende Verankerung im Volk, wie sie zu Zeiten der Republik durch die Abgeordneten gewährleistet gewesen sei. Um so bedeutsamer werde künftig die Rolle berufsständischer Vertretungen sein, die er prompt zu unterwandern trachtete ${ }^{86}$.

Die Entwicklung im Oktober 1940 schien auf Abetz' Vorstellungen zuzusteuern. Nach der Brenner-Konferenz zu Monatsbeginn, auf der Hitler den Italienern seine Kontinentalblockpläne erläuterte, meldete Stülpnagel zuversichtlich, „daß der Führer sich auf die Linie ,mit Frankreich' hat ziehen lassen“. Die Franzosen sollten für ein ,verkapptes Bündnis“ gewonnen werden und Zusagen erhalten, "welche weitgehend den Friedensschluß vorwegnehmen ${ }^{\text {" }}{ }^{7}$. Ganz so weit war die politische Willensbildung in Berlin zwar nicht gediehen, wie Heereschef v. Brauchitsch rasch herausfand - reges Interesse, eine Koalition gegen England zu schmieden, verzeichnete aber auch er ${ }^{88}$. Allerdings hing Hitler noch immer der verqueren Idee an, François-Poncet zu empfangen, der doch als Kritiker des ,Dritten Reiches' galt und damals keine amtliche Funktion mehr ausübte; von seinem letzten Posten als Präsident des Französischen Roten Kreuzes hatte ihn die Vichy-Regierung auf deutsches Geheiß entfernt ${ }^{89}$. Erst bei einem persönlichen Vortrag am 12. Oktober ist es Abetz offenbar gelungen, Hitler diesen Gesprächspartner auszureden. Zwei Treffen mit Staatschef Pétain wurden nun im Zuge einer Spanienreise ins Auge gefaßt, dazwischen wollte der ,Führer' mit Franco konfe-

85 „Politischer Lagebericht“; MAE, Papiers 1940, Papiers Abetz/2, auch zum Folgenden.

86 Die Konstanz seines Herrschaftsentwurfs belegt ein achteinhalb Monate später abgefaßter Bericht, in dem Abetz für sich reklamiert, national einheitliche Gewerkschaften, Korporationen, Frontkämpfer-Organisationen, Jugendverbände und Sammlungsbewegungen verhindert zu haben. „Lagebericht für den Herrn Reichsaußenminister", 23.6. 1941, ebenda.

87 KTB Halder, II, S. 129f. (8. 10. 1940).

88 Ebenda, S. 133 (11. Oktober).

89 Vgl. ADAP, D XI.1, S. 220, Anm. 19. 
rieren ${ }^{90}$. Pétain hatte seinen mehrfach geäußerten Wunsch einer Zusammenkunft soeben bekräftigt: Im Rundfunk verkündete er am 10. Oktober, Frankreich müsse sich aus traditionellen Freundschaften und Feindschaften lösen und sei bereit zur "collaboration", auf sämtlichen Gebieten und mit allen Nachbarn. Daran knüpfte er einen Appell an die Deutschen, althergebrachten Unterdrückungsmustern zu entsagen und einen "neuen Frieden der Zusammenarbeit" zu gewähren"1. Seine Worte waren nicht zuletzt für Hitler bestimmt und wurden im angelsächsischen Lager mit einiger Bestürzung registriert ${ }^{92}$.

Die Weichen für eine Aussprache auf höchster Ebene waren damit gestellt, und eine Kleinstadt nahe Tours rückte unversehens ins Blickfeld der Weltöffentlichkeit: Montoire-sur-le-Loir.

\section{Morgengrauen einer neuen Ära? Montoire und die Folgegespräche}

Paris, 22. Oktober 1940. Die Herbstsonne lacht. Gegen 9.30 Uhr verläßt ein Auto-Konvoi die Rue de Lille. Otto Abetz und seine engsten Mitarbeiter eskortieren den stellvertretenden Ministerpräsidenten Pierre Laval, begleitet von Fernand de Brinon, nach Tours. Von dort soll es weitergehen an einen geheimen Ort. Laval ist vorab nur gesagt worden, daß am Reiseziel der Reichsaußenminister warte. Erst in letzter Minute eröffnet ihm Abetz, auch der ,Führer' werde zugegen sein. „Sans blague - wirklich?!“ entfährt es dem überrumpelten Franzosen ${ }^{93}$.

Hitlers Sonderzug, unterwegs zur spanischen Grenze, hatte auf dem mit Grünpflanzen geschmückten Bahnhof von Montoire einen Halt eingelegt. Bei der Begrüßung im Salonwagen trat Laval, vom Blitzlichtgewitter mehrerer Fotografen geblendet, dem Diktator erst einmal unabsichtlich auf die Zehen ${ }^{94}$. Im Verlauf der zweistündigen Unterredung beteuerte er dann, daß er eine „rückhaltlose“ Zusammenarbeit anstrebe, die Frankreichs einzige Rettung sei. Er verurteilte die politischen Fehler der Vergangenheit, wünschte Englands Niederlage „von ganzem Herzen" herbei und versicherte, daß sich "alles erreichen" ließe, wenn die Deutschen die ausgestreckte Hand ergriffen und den geschlagenen Nachbarn einen ehrenvollen Frieden zubilligten. Damit verband er einmal mehr die Hoffnung, das

90 KTB Halder, II, S. 137 (15. Oktober), nach Informationen des Vortragenden Legationsrats v. Etzdorf. Davon abweichend wurde das erste Gespräch auf französischem Boden dann nur mit Laval geführt, den Abetz nochmals wärmstens empfahl; vgl. hierzu Duroselle, L'A bîme, S. 268.

91 Zitiert in Pétain, Actes et écrits, S. 472.

92 Kupferman, Laval, S. 263; Langer/Gleason, Undeclared War, S. 74.

93 Rudolf Schleier hat den Ereignissen vom 22. bis 24. Oktober in seinen Memoiren ein 15 seitiges Kapitel gewidmet, das Licht auf protokollarische Details und die übertriebenen Erwartungen im Stab des Botschafters wirft; PA/AA, Nachl. Schleier/IV.2, Nr. 13. Laval parle, S. 65, bestätigt das Überraschungsmoment. Zur Wahl Montoires als Treffpunkt Delpla, Montoire, S. $245 \mathrm{f}$.

94 So bezeugt gegenüber seinem späteren Verteidiger Jaffré; ders., Les derniers propos, S. 153. 
französische Kolonialreich, „unter Schmerzen“ aufgebaut und so kostbar wie eigen Fleisch und Blut, möge unangetastet bleiben. Hitler erwiderte ungerührt, „irgend jemand" müsse am Ende für die Kriegskosten haften. Je nachdem, ob Frankreich den letztlich siegreichen Kampf gegen England unterstütze oder auf Zeit spiele, würden seine Interessen in einer künftigen Friedensordnung berücksichtigt oder ignoriert ${ }^{95}$.

Beim abendlichen Diner mit Abetz äußerte sich Laval „sehr befriedigt" über die Aussprache ${ }^{96}$. Der ersehnte persönliche Kontakt zur Reichsführung war endlich hergestellt, nun bot sich aus seiner Sicht die Chance zu verhandeln. Außerdem war ein Treffen mit Marschall Pétain für den übernächsten Tag avisiert worden. Nach Konsultationen in Spanien wollte Hitler den französischen Staatschef auf der Rückfahrt - ebenfalls in Montoire - empfangen. Das elektrisierte die Befürworter der Kollaboration in beiden Lagern, zumal Hitler ebenso vage wie verlokkend angemerkt hatte, daß er jahrelangen Fehlschlägen zum Trotz weiter auf Annäherung bedacht wäre, "wenn sich die Voraussetzungen dafür finden ließen“. Schleier gewann den Eindruck, daß eine entscheidende Weggabelung im deutschfranzösischen Verhältnis erreicht sei97. Laval eilte am 23. Oktober in Begleitung Achenbachs und Brinons nach Vichy, wo die Gerüchteküche brodelte, und verkündete strahlend die Neuigkeit vom bevorstehenden Treffen der Staatschefs, eine Nachricht, die etliche Minister, über den neuerlichen Alleingang ihres Kollegen erbost, mit heftigem Unmut quittierten ${ }^{98}$. Das Mißtrauen wuchs, als Laval voller Begeisterung von einer Kollaborationsofferte des ,Führers' berichtete, ohne sagen zu können, was genau darunter zu verstehen sei99. Pétain jedenfalls stimmte zu, Hitler zu sehen, und verzichtete auf Drängen Lavals sogar darauf, den amtierenden Außenminister Baudouin mitzunehmen, was diesen, von seinem Rivalen beständig überspielt und nun mit der Möglichkeit einer prodeutschen Ausrichtung der Vichy-Regierung konfrontiert, zum Rücktritt trieb ${ }^{100}$. Abetz und Laval dürften es mit Genugtuung registriert haben.

Am Morgen des 24. Oktober fuhr Pétain mit kleinem Gefolge nach Tours und hielt sich in der Präfektur bereit. Ein stundenlanges Warten hob an, weil zunächst nur der ,Führer'-Zug in Montoire eintraf, während Ribbentrop noch in Spanien verhandelte und verspätet mit dem Flugzeug ankam. Um Pétain zu zerstreuen, stattete Abetz ihm zwischendurch einen Höflichkeitsbesuch ab. Es war die erste Begegnung der beiden. „Der Marschall“, notierte Schleier, "machte trotz der für ihn nur kurzen Nacht [...] einen ungewöhnlich frischen Eindruck, war allerdings sichtbar nervös. "101 Endlich, gegen 17 Uhr, das Signal zum Aufbruch. Auf dem Bahnhof von Montoire mit militärischen Ehren begrüßt, wurde Pétain von Ribbentrop und Keitel zu Hitler geleitet. Marschall und Weltkriegsgefreiter reichten

\footnotetext{
95 Aufzeichnung Schmidt vom 22. 10. 1940; ADAP, D XI.1, Nr. 212.

96 Schleier, "Montoire", pag. 4.

97 Ebenda, pag. 5.

$98 \mathrm{Vgl}$. Duroselle, L'Abîme, S. 268.

99 Aron, Histoire de Vichy, S. 292 f.

100 "Il ne peut y avoir deux ministères des Affaires étrangères." Baudouin, Neuf mois, S. 382.

101 Schleier, „Montoire“, pag. 8.
} 
einander symbolträchtig die Hand, was viele voreilig als Beginn einer neuen Ära deuteten. In der folgenden Unterredung fand sich der Gast aus Vichy „im Prinzip" zu einer Zusammenarbeit bereit, wobei ihm - durchgängiges Motiv für die französischen Avancen - besonders am Erhalt der afrikanischen Kolonien und an Lockerungen des Besatzungsregimes gelegen war. Hinsichtlich der Modalitäten aber mochte er sich ohne vorherige Beratung mit seiner Regierung in keiner Weise binden. Laval unterstrich die Möglichkeit eines militärischen Engagements, ohne daß sein Land sofort den offenen Kriegszustand mit England auszurufen brauche, empfahl anderseits jedoch eine behutsame Einstimmung der französischen Öffentlichkeit auf gemeinsame Schritte und erinnerte an eine konstitutionelle Hürde: Pétain könne nur mit Zustimmung des überkommenen Parlaments den Krieg erklären, ein Procedere, zu dem man begreiflicherweise nicht die geringste Neigung verspüre. Hitler für seinen Teil verwies auf die deutschen Rüstungszahlen und schilderte Britanniens Lage als ausweglos. Doch sei es sein Bestreben, den Kampf, der nur immer neue Folgelasten verursache, abzukürzen. Zu diesem Zweck sollten sich die europäischen Nationen in einer "natürlichen Gemeinschaft" gegen den Kontinentalfeind formieren. Er sei im Begriff auszuloten, in welchem Maße Frankreich hierbei mitwirken wolle ${ }^{102}$. Das war wesentlich einladender formuliert als zwei Tage zuvor, vielleicht als Folge der soeben gescheiterten Verhandlungen über Spaniens Kriegseintritt ${ }^{103}$, vielleicht aus Respekt vor Pétain. Im Kern allerdings ging es dem ,Führer' unverändert darum, der deutschen Kriegsmaschinerie zusätzliche Ressourcen zu erschließen, ohne daß er sein Bild vom Erbfeind revidiert hätte ${ }^{104}$. Der Marschall mied umgekehrt jede vorschnelle Verpflichtung; während Laval sich offensiv und auf Konzessionen erpicht deutschen Kriegszielen verschrieb, taktierte er behutsam nach allen Seiten und war stets bemüht, auch mit London und Washington in Verbindung zu bleiben ${ }^{105}$.

Trotz aller Vagheiten und Hintergedanken aber hatte es den Anschein, als könnte die Kollaboration feste Konturen annehmen - nie wieder, resümierte Abetz später, seien die Voraussetzungen günstiger gewesen als in den Tagen von Montoire106, die für alle Kollaborateure zum Bezugspunkt ihrer Politik wurden ${ }^{107}$. Im Dunstkreis der Botschaft herrschte naturgemäß Hochstimmung, da man das Ziel dicht vor Augen sah. Dieser Tag bedeute eine Wende im deutschfranzösischen Verhältnis, meinte Brinon tiefergriffen auf der Rückfahrt von Montoire ${ }^{108}$. Marcel Déat kündete in L'Euvre vom „Morgengrauen einer neuen Ära“.

102 Vgl. Aufzeichnung Schmidt, 24. 10. 1940; ADAP, D XI.1, Nr. 227.

103 Zur Konferenz von Hendaye am 23. 10. 1940 siehe Geschke, Frankreichpolitik, S. $89 \mathrm{ff}$.; Detwiler, Hitler, Franco und Gibraltar, S. 113 ff.; ADAP, D XI.1, Nr. 220-222.

104 Die Überzeugung, daß eine dauerhafte Annäherung ausgeschlossen sei, bestimmte unverändert sein Denken. Vgl. KTB Halder, II, S. 137 (15. Oktober): „Im ersten möglichen Augenblick wird der Revanchegedanke wieder durchbrechen."

105 Ein beredtes Beispiel hierfür ist die Rougier-Mission in London, die fast parallel zum Treffen von Montoire unternommen wurde. Siehe Krautkrämer, Kriegswende, S. $50 \mathrm{ff}$.; Robert Frank, Vichy et les Britanniques 1940-1941, in: Azéma/Bédarida (Hrsg.), Vichy et les Français, S. $144 \mathrm{ff}$.

106 Abetz-Prozeß, 13. 7. 1949, pag. 47 f.; AN, 334 AP 49.

107 Brender, Kollaboration, S. 112, dort auch das folgende Déat-Zitat.

108 Schleier, "Montoire“, pag. 10. 
Laval, vom 28. Oktober an auch für das Außenressort verantwortlich, berichtete dem Ministerrat in Vichy und strotzte vor Zuversicht, wie Darlans Aufzeichnungen belegen: „Si la France collabore avec l'Allemagne, la paix sera douce et nous conserverons notre Empire." ${ }^{109}$ Die schlichte Formel spiegelte Wunschdenken, nicht den Stand der Gespräche, und entpuppte sich rasch als Trugbild, ähnlich den in der Rue de Lille gehegten Hoffnungen. „Wir glaubten nach dem Verlauf dieser Begegnungen, daß Hitler aufrichtig entschlossen war, Frankreich die Hand zur Versöhnung hinzustrecken", betonte Schleier ${ }^{110}$. Auch Otto Abetz konnte sich in seiner Mission bestärkt fühlen, Frankreich als Satelliten im großdeutschen Orbit zu verankern, in fortan friedlicher Koexistenz mit dem östlichen Nachbarn, jedoch unentrinnbar dessen Gravitationsfeld zugeordnet, politisch, wirtschaftlich und ideologisch. Rückenwind erhielt der Botschafter zum damaligen Zeitpunkt von Wehrmacht-Offizieren, die sich seinem vergleichsweise gemäßigten Kurs angenähert hatten und brennend an einer militärischen Kooperation im Mittelmeerraum interessiert waren. „Die Zivilisten in der Umgebung des Führers sind die Scharfmacher gegenüber Frankreich“, notierte Halder am 17. Oktober. „Die führenden Leute des Heeres vertreten die gegenteilige Auffassung und sind damit auf gleicher Linie wie Abetz." ${ }^{111}$ Dasselbe schien für das Auswärtige Amt zu gelten: Mitarbeiter Ribbentrops formulierten auf der Reise nach Montoire Entwürfe für Abmachungen, die wohl unschwer das Placet des Pariser Kollegen fanden. Die Franzosen, hieß es da, sollten Deutschland „im Rahmen ihrer Möglichkeiten“ unterstützen, die Kolonien verteidigen und dafür konkrete Erleichterungen sowie einen "gebührenden Platz" im künftigen Europa zugesichert bekommen ${ }^{112}$. Abetz kannte die Entwürfe und hob später gern auf ein fiktives Protokoll der Montoire-Gespräche $a b$, das Frankreich zu den europäischen Kernmächten zählt ${ }^{113}$. Dabei erweckte er den falschen Eindruck, das Dokument sei erst nach den Konferenzen mit Laval und Pétain entstanden und ein offizielles Papier gewesen, vermutlich um den Verständigungswillen der deutschen Diplomaten zu untermauern ${ }^{114}$.

Propagandistisch holte Abetz im Herbst 1940 zu einer neuen Offensive aus, die seine und Lavals Kollaborationspläne stützen sollte. Die Tageszeitung Les Nouveaux Temps, unter Patronage der Botschaft von Jean Luchaire gegründet, erschien erstmals am 1. November und leistete umgehend publizistischen Flankenschutz für den vermeintlich hoffnungsvollen Ansatz von Montoire ${ }^{115}$. Mit dem Gedanken, seinen Intimus hilfreich in das eigene Wirken einzubinden, hatte der

109 Darlan, Lettres et notes, S. 200.

110 Schleier, pag. 14, die Hervorhebung im Original.

111 KTB Halder, II, S. 142.

112 Abgedruckt ADAP, D XI.1, Nr. 206 ff. Zur zeitlichen Zuordnung der Dokumente, die weder Verhandlungsgrundlage waren noch den Franzosen ausgehändigt wurden, Jäckel, Frankreich, S. $111 \mathrm{ff}$.

113 Ein handschriftlicher Randvermerk auf dem abgedruckten Exemplar besagt: „Original bei Abetz, nicht überreicht." ADAP, D XI.1, S. 297, Anm. 1.

114 Abetz-Memorandum 1943, pag. 11f.; Das offene Problem, S. 157. Abetz-Prozeß, 13. 7. 1949, pag. $46 \mathrm{ff}$.; AN, 334 AP 49.

115 Vgl. die Auswertung der ersten Nummern durch Lévy, Les Nouveaux Temps, S. 93 ff. 
Botschafter offenbar schon vor Monaten gespielt, nicht allein aus politischen Erwägungen, sondern auch, um sich dankbar zu zeigen. Ausdrücklich würdigte er nach dem Krieg die Tatsache, daß Luchaire ihm während der Ausweisungsaffäre 1939 die Stange gehalten hatte - Nibelungentreue, die ebenso verpflichtete wie die Kurierdienste zwischen der Rue de Lille und Laval ${ }^{116}$. Die nie ganz geklärte Anschubfinanzierung der Nouveaux Temps nährte Spekulationen, die Zeitung sei ein persönliches Geschenk Abetz' an den alten Weggefährten gewesen ${ }^{117}$. Nach den Worten Luchaires zögerte der Freund zunächst, das Blatt zu lancieren, warnte vor einem verlegerischen Abenteuer und gab erst grünes Licht, als sich deutsch-französische Gespräche auf höchster Ebene abzeichneten: „Maintenant il y a quelque chose de substantiel, ce n'est pas une chimère, ce n'est pas un trompe-l'œil, on peut marcher." In der zweiten Oktoberwoche - die Vorbereitungen mußten weit gediehen sein - stimmte die Propaganda-Abteilung beim Militärbefehlshaber, Wächterin über Drucklizenzen und Papierzuteilung, dem Vorhaben zu118. Am 31. Oktober dann die freudige Mitteilung Luchaires: „Mon cher Otto, voici mon premier numéro. Je serais heureux de pouvoir te joindre quelques minutes pour savoir ce que tu en penses..." 119 Fortan entfalteten Les Nouveaux Temps ein propagandistisches Trommelfeuer im Sinne der Botschaft, mit nachgerade erschrekkender Konsequenz das längst pervertierte Leitmotiv eines ,neuen' Europa preisend. Die Zeitung erschien bis zum Rückzug der Wehrmacht aus Paris im August 1944, die Auflage schwankte zwischen 35000 und 62000 Exemplaren ${ }^{120}$.

Die spannendste Frage im Herbst 1940 aber lautete: Was würde auf Montoire folgen? Am 30. Oktober forderte Pétain die Franzosen in einer Rundfunkrede auf, Vertrauen in die "neue Politik“ zu setzen, die die Leiden des Landes verringern solle; die Zusammenarbeit müsse allerdings aufrichtig sein und jeden feindseligen Gedanken ausschließen ${ }^{121}$. Tags darauf begann in Paris eine Serie von Folgeverhandlungen zwischen Diplomaten und hochrangigen Militärs ${ }^{122}$. Abetz und Laval brannten darauf, zu konkreten Ergebnissen zu kommen - nur mit Erfolgen konnten sie ihren von vielen beargwöhnten, wenn nicht angefeindeten Kurs be-

116 Vgl. Abetz' Aussage im Luchaire-Prozeß, 22. 1. 1946; Les procès de collaboration, S. 490.

117 Laut Weil-Curiel, Le temps de la honte, II, S. 263, hat Abetz diese Version selber verbreitet. Einen vergleichbaren Schluß zog Eugen Feihl in seiner Vernehmung am 1. 9. 1946; $\mathrm{AN}, 3 \mathrm{~W}$ 358. Luchaires anderslautende Version in Les procès de collaboration, S. $381 \mathrm{f}$; dort auch das folgende Zitat. Kritische Bewertung der Geldquellen von Lévy, Les Nouveaux Temps, S. $40 \mathrm{f}$.

118 „Tätigkeitsbericht der Propaganda-Abteilung Frankreich für die Zeit vom 7. 10.-13. 10. 1940", pag. 11; AN, AJ 40/1001.

119 Gouvernement Provisoire de la République Française, Dossier „Relations entre Otto Abetz, Jean Luchaire, Fontenoy et autres journalistes collaborateurs", 31. 10. 1945; AN, F $7 / 15331$.

120 Lévy/Michel, La presse autorisée de 1940 à 1944, in: Histoire générale de la presse française, IV, S. 48.

121 Pétain, Actes et écrits, S. 549 f.

122 Für Einzelheiten sei aus Platzgründen verwiesen auf Jäckel, Frankreich, S. $127 \mathrm{ff}$.; Geschke, Frankreichpolitik, S. 106 ff.; Paxton, Vichy France, S. 77 ff.; Delpla, Montoire, S. $348 \mathrm{ff}$;; Krautkrämer, Entmachtung Lavals, S. $91 \mathrm{ff}$., sowie die einschlägigen Dokumente in den Akten zur deutschen auswärtigen Politik. 
haupten und Wankelmut und Halbherzigkeit in Vichy und Berlin überwinden. Die Gespräche vor Ort entwickelten sich durchaus konstruktiv, im Ton verbindlich, doch krankten sie an einem grundsätzlichen, während der gesamten Okkupation nie überwundenen Zwiespalt: Es saßen keine gleichberechtigten Partner am Tisch. In der Reichshauptstadt erwartete man zudem sofortige militärische Hilfeleistungen, während Lockerungen des Besatzungsregimes bestenfalls als deren Folge in Aussicht gestellt wurden. Eine ,Führer-Weisung' vom 12. November brachte die einseitige Haltung auf den Punkt: Als Ziel seiner Frankreichpolitik definierte Hitler hier, „mit diesem Land in einer für die zukünftige Kriegführung gegen England möglichst wirkungsvollen Weise zusammenzuarbeiten. Frankreich wird dabei vorläufig die Rolle einer ,nicht kriegführenden Macht ${ }^{6}$ zufallen, die in ihrem Hoheitsgebiet, besonders in den afrikanischen Kolonien, Maßnahmen der deutschen Kriegführung zu dulden und, soweit erforderlich, auch durch Einsatz eigener Verteidigungsmittel zu unterstützen hat." 123 Diese Aufgabenstellung erforderte eine Verstärkung der französischen Streitkräfte, was dem tiefen Mißtrauen der Deutschen gegen den Generaldelegierten in Afrika, General Weygand, zuwiderlief, dem man schlankweg zutraute, er werde die Kolonien nicht verteidigen, sondern den Alliierten in die Hände spielen. Von Leistungsanreizen war ohnehin keine Rede; die geschlagenen Nachbarn hatten sich jeder Vergünstigung erst einmal „würdig zu erweisen“, so eine gängige Maxime, die der Überheblichkeit eines Diktators entsprang, der es gewohnt war, seinen Willen mit Gewalt durchzusetzen, der nicht auf die Siegesbeute verzichten mochte und keineswegs aufhörte, strategische Alternativen im Kampf gegen England zu prüfen. Eine Unterredung Lavals mit Göring am 9. November blieb ebenfalls ohne Impulse ${ }^{124}$. Auch Ribbentrop beschränkte sich auf das Abblocken französischer Wünsche, verschleppte ein zweites Treffen mit Laval und torpedierte so die Bemühungen seines Pariser Statthalters, dessen Position vordergründig noch einmal aufgewertet wurde: Abetz' „Dienststelle“ hieß vom 20. November an offiziell „Deutsche Botschaft", und ihr Leiter sollte nun „für die Behandlung aller politischen Fragen im besetzten und unbesetzten Frankreich" verantwortlich sein ${ }^{125}$.

Welchen Schaden die deutsche Haltung anrichten konnte, illustriert ein Brief des Botschaftsangehörigen Dr. Karl-Heinz Gerstner, Mitglied der Wirtschaftsabteilung, an den späteren Zweigstellenleiter in Vichy, Roland Krug v. Nidda. Während die Gespräche von Montoire doch wohl nur die allgemeinen Linien einer $\mathrm{Zu}$ sammenarbeit behandelt hätten, schrieb Gerstner am 6. November 1940, sei die deutsche Propaganda in Frankreich sofort danach „in ein solches Triumphgeschrei ausgebrochen, daß überall hier der Eindruck entstanden ist, als stehe der Friedensschluß mit Frankreich unmittelbar bevor“. Dergestalt sei mit dem Wort

123 Hubatsch (Hrsg.), Hitlers Weisungen für die Kriegführung, Nr. 18, S. 77.

124 Eine Aufzeichnung des Gesprächs in: ADAP, D XI.1, Nr. 306.

125 "Führerentscheid" vom 20.11. 1940, abgedruckt ADAP, D XI.2, Nr. 368. Zu Ribbentrops Instruktionen vermerkte Botschafter Ritter in Berlin am 8.11.1940, es dürften „nur technische vorbereitende Besprechungen" stattfinden, wobei der Gegenseite klar gesagt werden müßte, es handele sich nicht um, Verhandlungen‘. Die könnten „erst nach einer vorherigen allgemeinen politischen Klärung geführt werden“. PA/AA, R 29608. 
"collaboration" erheblicher Mißbrauch getrieben worden - ein Urteil, das die Botschaft mitnichten ausklammerte. Die Folgen waren laut Gerstner fatal: „Die Franzosen erwarten allgemein eine sofortige Besserung ihrer Lage und es laufen die wildesten Gerüchte um: z. B.: die französische Regierung sei bereits unterwegs von Vichy, um sich in Paris oder Versailles einzurichten. Die deutsche Besatzung wäre eingeschränkt, ja es wird sogar schon auf Evakuierung angestoßen. Überall wird erzählt, eine unmittelbare Folge der Besprechung sei die sofortige Freilassung sämtlicher französischen Kriegsgefangenen. Die Demarkationslinie wäre abgeschafft, Frankreich behalte sein gesamtes Kolonialreich, Deutschland erhalte allenfalls das Elsaß. Vor allen Dingen werden unmittelbar wirtschaftliche Hilfsaktionen und Erleichterungen erwartet." Da sich in Wahrheit überhaupt nichts rühre, reagierten die Leute nun bereits verbittert und beschuldigten die Deutschen, „entweder Marschall Pétain hereingelegt oder sonst ein unehrliches Spiel getrieben zu haben. Es ist mit Bestimmtheit anzunehmen, daß diese Enttäuschung sich noch wesentlich verstärken wird." Finanzminister Bouthillier befürchte den „völligen Zusammenbruch der öffentlichen Meinung, wenn nicht in den nächsten Tagen wenigstens etwas geschieht" 126 .

Auf Taten drängte unermüdlich auch Pierre Laval. Während eines Frühstücks mit Schleier, Brinon und Fliegergeneral Hanesse am 3. Dezember gab er seiner Hoffnung Ausdruck, in Kürze Ribbentrop zu treffen und von ihm ein "wertvolles Zugeständnis“ zu erlangen, das er den Franzosen „als Geschenk“ mitbringen könne. Sobald er diese Frucht der deutsch-französischen Zusammenarbeit in Händen halte, werde er in aller Deutlichkeit zu seinen Landsleuten sprechen, von denen in absehbarer Zeit wenigstens 80 Prozent für ein Zusammengehen mit dem Reich zu gewinnen seien. Damit sein Appell den gewünschten Erfolg habe, dürfe er allerdings nicht mit leeren Händen aus Berlin zurückkehren ${ }^{127}$. Dies zu verhindern, trat Laval sogar bereitwillig in Vorleistung. Ende November sorgte er dafür, daß die von der Banque de France verwahrten Goldbestände der belgischen Nationalbank in deutsche Hände fielen ${ }^{128}$. Desgleichen stimmte er dem Verkauf der französischen Anteile an den im jugoslawischen Bor gelegenen Kupferminen zu, die zwei Drittel des Eigenbedarfs deckten und in der Handelsbilanz mit jährlich 200 Millionen Francs zu Buche schlugen ${ }^{129}$. Besonders Göring und die Wiesbadener Wirtschaftsdelegation drängten seit Monaten auf eine Übernahme. Nun wanderten 440000 Aktien, überwiegend im Besitz des Pariser Bankhauses Mirabaud, für 1,75 Milliarden Francs an ein deutsches Konsortium; bezahlt wurde mit Besatzungsgeld. Der Transfer bildete 1949 einen Anklagepunkt im Abetz-Prozeß. Der

126 Gerstner an Krug, 6. 11. 1940; PA/AA, Botschaft Paris 1270. Das Dokument trägt Gerstners privaten Briefkopf. Ähnliche Risiken sah auch Laval: Es bestehe die Gefahr, daß dem übertriebenen Pessimismus der Franzosen nun ein übertriebener Optimismus folge, der leicht in Enttäuschung umschlagen könne, warnte er seine deutschen Gesprächspartner am 31. Oktober; ADAP, D XI.1, Nr. 272.

127 Schleier, „Notiz für Herrn Botschafter", 3. 12. 1940; PA/AA, Botschaft Paris 1271.

128 Krautkrämer, Entmachtung Lavals, S. 93; Jäckel, Frankreich, S. 137; Aron, Histoire de Vichy, S. 315 f.; Duroselle, L'Abîme, S. 272 f. Erfolgsmeldung von Abetz und Hemmen an das Auswärtige Amt, 30. 11. 1940; IMT, EC-54.

129 Bouthillier an Laval, 28. 11. 1940; MAE, Papiers 1940, Papiers Laval/2. 
Botschafter, so der Vorwurf, habe bei den Bor-Minen Druck auf Laval ausgeübt und sich der wirtschaftlichen Ausbeutung schuldig gemacht ${ }^{130}$. Abetz hat das bestritten; seine Angaben bei einem Verhör im Jahr 1945 lassen aber zumindest erkennen, daß er Laval eindringlich darauf hinwies, welch positiven Einfluß ein Mann wie Göring auf die Gestaltung des Besatzungsregimes nehmen könnte, käme man seinen Wünschen entgegen ${ }^{131}$.

\section{5. "Ein Verbrechen an Frankreich“: Der 13. Dezember und der Sturz Lavals}

Es ist müßig, an dieser Stelle auf die wechselseitigen Forderungen der Pariser Unterhändler im Spätherbst 1940 einzugehen - sie blieben allesamt Theorie. Die Reichsregierung zeigte kein Interesse an der Erörterung politischer Fragen, die französischen Militärs taktierten im Gegenzug zusehends vorsichtiger ${ }^{132}$. Hinzu kam ein Ereignis, das in ganz Frankreich Empörung auslöste und Lavals Position empfindlich untergrub, weil es als direkte Folge seines Tuns interpretiert wurde: die Vertreibung von rund 60000 Lothringern aus ihrer Heimat im November ${ }^{133}$. Seit Monaten bereits wurden jüdische und frankophone Einwohner aus dem de facto annektierten Landstrich und dem benachbarten Elsaß ins unbesetzte Frankreich ausgewiesen; nun aber, just als die Folgegespräche von Montoire anliefen, erreichte die Germanisierungswelle ihren unrühmlichen Höhepunkt, holte Gauleiter Josef Bürckel, Chef der lothringischen Zivilverwaltung, zum großen Schlag aus. Am 31. Oktober informierte er Abetz, daß schon am 4. November mit der „Aussiedlung“ von 100000 „französisch gesinnten“ Menschen begonnen werde. Den Botschafter entsetzte dieser Plan, nicht aus humanitären Gründen, sondern ob des unpassenden Zeitpunkts; er sah das zarte Pflänzchen der Kollaboration akut gefährdet. Eilends bat er deshalb Ribbentrop, die Aktion auf einen politisch günstigeren Termin zu verschieben ${ }^{134}$. Auch die Waffenstillstandskommission in

130 Anklageschrift vom 20.6. 1949, pag. 76; Verhandlungsprotokoll vom 13.7. 1949, pag. $149 \mathrm{ff}$; AN, 334 AP 49.

131 Verhörprotokoll Nr. 204/20 der Sûreté Nationale vom 22. 11. 1945, „Renseignements sur les conditions dans lesquelles fut projetée la cession d'actions des mines de Bor à l'Allemagne“; AN, F 7/15331.

132 Vgl. die zitierte Sekundärlite:atur sowie ADAP, D XI.1, Nr. 272, 285, 298, 321; XI.2, Nr. 401, 428, 434, 490. Daß Laval auf eine weitgehende Befreiung Frankreichs aus den Fesseln des Waffenstillstandsvertrags zielte, belegt beispielhaft ein als Verhandlungsgrundlage dienendes Memorandum vom 24. 11. 1940. Darin sind folgende Wünsche aufgelistet: einheitliche Verwaltung des Landes; Wiedereingliederung der Départements Nord und Pas-de-Calais; freier Waren- und Personenverkehr; Zollhoheit; keine weiteren Requisitionen; französische Mitsprache bei deutschen Einkäufen im Lande; Rückgabe von Lokomotiven und Waggons; Halbierung der Besatzungskosten; günstigerer Wechselkurs. MAE, Papiers 1940, Papiers Laval/1.

133 Diese Zahl nach Barral, L'Alsace-Lorraine, S. 241.

134 Abetz an Auswärtiges Amt, 1. 11. 1940; ADAP, D XI.1, Nr. 271. In seiner Denkschrift von 1943 ließ er keinen $Z$ weifel an seiner Sichtweise: „An sich war diese Maßnahme völlig 
Wiesbaden protestierte. Postwendend indes kam die niederschmetternde Nachricht aus Berlin, Hitler habe "trotz der von Ihnen vorgebrachten Bedenken auf Vortrag des Reichsaußenministers entschieden, daß die Aussiedlung der Lothringer sofort durchgeführt werden soll“. Abetz möge die Regierung Pétain „inoffiziell und in freundschaftlicher Weise" verständigen. Zugleich wurde ihm die Verbreitung der Lüge anheimgestellt, die Leute wollten freiwillig nach Frankreich zurückkehren ${ }^{135}$. Es ist Abetz lediglich gelungen, die Deportationen noch ein paar Tage hinauszuzögern, indem er Bürckel zu einer Besprechung mit Laval über Zeitpunkt und Tempo überredete. Doch auf Anraten Ribbentrops widerrief der Gauleiter, im Urteil Schleiers „eine primitive und brutale Persönlichkeit“, diese Zusage wieder ${ }^{136}$. Am 11. November rollten die ersten Transporte, am 30. des Monats verkündete Bürckel bei einem Aufmarsch der NSDAP in Saarbrücken, an Deutschlands künftiger Westgrenze herrschten jetzt „für alle Zeiten klare Verhältnisse“. Eine „kristallklare“ ethnische Säuberung sei nötig gewesen, um „einen Westwall deutschen Blutes und unzertrennlicher Treue zu errichten"137.

Die Rückwirkungen in Vichy waren beträchtlich. Besonders erzürnt war der Ministerrat über deutsche Behauptungen gegenüber Vertriebenen, ihre Evakuierung gehe auf ein Regierungsabkommen zurück ${ }^{138}$. Eine offizielle Protestnote, in Wiesbaden überreicht, verurteilte die Aktion als Bruch des Völkerrechts und des Waffenstillstandsvertrags; darüber hinaus stehe sie in eklatantem Widerspruch zum Postulat der Zusammenarbeit ${ }^{139}$. Laval versuchte zur Tagesordnung überzuleiten, indem er Schleier erklärte, es sei wichtig, die Sache nicht zu dramatisieren und entschlossen an der Politik von Montoire festzuhalten. Doch bat er im selben Gespräch darum, die Transporte vorläufig auszusetzen - eine solche Geste sei für seine persönliche Stellung „besonders wertvoll“ 140 . Sie wankte offenbar bedrohlich, wie Darlans knappes Resümee erahnen läßt: „Si c'est ainsi que les Allemands comprennent la ,collaboration", la politique de M. Laval a fait fiasco."141 Für Schleier war die Bürckel-Kampagne ein besatzungspolitisches Desaster: „Die Ausgetriebenen wurden über das ganze unbesetzte französische Gebiet verteilt [...] Überall dort, wo Elsäßer und Lothringer hinkamen, bildeten sie aus ihrem persönlichen Erleben die Keimzellen der Widerstandsbewegung." Zugleich übte er harsche Kritik an Ribbentrop, der die Botschaft schmählich im Stich ließ; „Wie stets in derartigen Fällen wagte er nicht, einer angeblichen Führerentscheidung zu widersprechen, und wollte vor allen Dingen nicht als weicher oder nachgiebiger

selbstverständlich [...] Schwerwiegend aber war der Moment der Aussiedlungsaktion“. Abetz-Memorandum 1943, pag. $26 \mathrm{f}$.

135 Gaus (Berlin) an Abetz, 2. 11. 1940; ADAP, D XI.1, Nr. 278.

136 Bürckel an Ribbentrop, 15. 11. 1940, ebenda, D XI.2, Nr. 337. Schleier, „Die Lothringer Austreibung durch Bürckel“; PA/AA, Nachl. Schleier/IV.5.

137 DNB Saarbrücken, 30. 11. 1940: „Abschlußbericht von Gauleiter Bürckel über die Umsiedlung in Lothringen"; PA/AA, R 29608. Vgl. Wolfanger, Nationalsozialistische Politik in Lothringen, S. $146 \mathrm{ff}$.

138 Kategorisches französisches Dementi abgedruckt in: Schleier an AA, 14. 11. 1940; ADAP, D XI.2, Nr. 331.

139 Doyen an Stülpnagel, 18. November; MAE, Papiers 1940, Papiers Laval/2.

140 Schleier für Abetz, 15. November; ADAP, D XI.2, Nr. 338.

141 12. November; Darlan, Lettres et notes, S. 202. 
Außenminister gelten."142 Abetz äußerte rückblickend die Überzeugung, der Vorfall habe wesentlich zum Sturz Lavals beigetragen ${ }^{143}$.

Die Entlassung, häufig als „Palastrevolution“ bezeichnet, traf Laval völlig unvorbereitet. Am Abend des 13. Dezember 1940 wurde er während eines kurzfristig einberufenen Ministerrats in Vichy handstreichartig abserviert ${ }^{144}$. Leichenblaß und außer sich stürmte er in Brinons Büro: „Ich bin gefeuert!"145 Die Gründe waren innerer wie außenpolitischer Natur. Staatschef Pétain war des ewigen Zigarettenqualms seines designierten Nachfolgers wohl genauso überdrüssig wie der ständigen Sorge, unzureichend informiert und vor vollendete Tatsachen gestellt zu werden. Als offensiver Verfechter der Kollaboration mit Deutschland hatte sich Laval mehr und mehr von der vorsichtig-abwartenden Haltung des Marschalls entfernt, ohne irgendein greifbares Resultat vorweisen zu können. Privilegierte Kontakte nach Paris und seine Konzessionsbereitschaft trugen ihm Neid, Mißtrauen und schließlich die blanke Opposition etlicher Kabinettskollegen ein, die ein regelrechtes Komplott schmiedeten. Möglicherweise den Ausschlag gaben die Amerikaner, die Laval als Parteigänger Hitlers einstuften und rundweg ablehnten. In Washington wurde seine Entmachtung gleichsam zur Bedingung erhoben, wollten sich die Franzosen nicht jegliches Wohlwollen der USRegierung und die Chance auf einen Modus vivendi mit den Briten verscherzen; beides schien unverzichtbar, um die Autorität in Afrika zu behaupten und die wirtschaftliche Lage der Kolonien zu verbessern ${ }^{146}$. Die offizielle Begründung für den Sturz lieferte ein persönliches Schreiben Pétains an Hitler, in dem es hieß, Laval besitze nicht mehr genügend Rückhalt im Land, um die Zusammenarbeit „zu einem guten Ende zu führen. Seine Arbeitsmethoden und seine Geisteshaltung, die Beziehungen, die er in gewissen politischen Kreisen aufrechterhalten hat, machen seine Person den Franzosen zu verdächtig, als daß nicht das Werk, dem er sich gewidmet hat, darunter tatsächlich Einbuße erleidet."147

Den letzten Anstoß, Laval kaltzustellen, gab ausgerechnet eine deutsche Geste, der in der Rue de Lille hohe politische Bedeutung beigemessen wurde. Am

142 Schleier, „Die Lothringer Austreibung“, wie Anm. 136.

${ }^{143}$ Schuchardt, „Aufzeichnung über Unterredung zwischen Obstlt i.G. Dr. Speidel und Botschafter Abetz am 9. 1. 1941"; AN, AJ 40/1202. Wohl kaum den Tatsachen entspricht Abetz' Behauptung, er habe bei Hitler "nach zehn Tagen vergeblichen Wartens" den Stopp der Vertreibungen erwirkt (Das offene Problem, S. 168). Exakt nach dieser Zeitspanne wurde die Bürckel-Aktion zwar für beendet erklärt, doch hatte Hitler sie ausdrücklich gutgeheißen. Vgl. KTB OKW, I, S. 146 (Eintrag vom 1. 11. 1940).

144 Vgl.die Schilderung Darlans, Lettres et notes, S. 204. Einzelheiten aus erster Hand erfuhren Abetz und seine Mitarbeiter am späten Nachmittag des 14. Dezember, nachdem Brinon aus Vichy nach Paris zurückgekehrt war. Schleier, „Der 13. Dezember 1940“ (18 S.), pag. 11; PA/AA, Nachl. Schleier/IV.1, auch zum Folgenden.

145 Brinon, Mémoires, S. $52 \mathrm{f}$.

146 Grundlegend zum außenpolitischen Kalkül hinter Lavals Sturz Krautkrämer, Entmachtung, besonders S. 95 ff.; ferner Jäckel, Frankreich, S. 140 ff.; Duroselle, L'Abîme, S. 272 ff.; Cointet, Laval, Kap. IX; Kupferman, Laval, S. 273 ff.; Warner, Laval, S. 253 ff.; Aron, Histoire de Vichy, S. $320 \mathrm{ff}$;; Mallet, Laval, I, S. $286 \mathrm{ff}$;; Laval parle, S. $73 \mathrm{ff}$., sowie die Memoiren von Baudouin, Bouthillier, Brinon und du Moulin de Labarthète.

147 Marschall Pétain an den Führer, 13. 12. 1940; ADAP, D XI.2, Nr. 510. 
15. Dezember 1940 jährte sich zum hundertsten Mal die Überführung der Gebeine Napoleons von Sankt Helena in den Invalidendom. Zu diesem Jubiläum sollte nun die sterbliche Hülle seines Sohns, des Herzogs von Reichstadt, aus der Wiener Kapuzinergruft an die Seite des Vaters umgebettet werden ${ }^{148}$. Hitler lud Pétain äußerst kurzfristig am 13. Dezember ein, der Zeremonie in Paris beizuwohnen. Es wäre die erste Visite des Marschalls im besetzten Gebiet gewesen. Laval und Brinon rieten nach Kräften zu und hatten auch zunächst Erfolg damit $^{149}$. Dann aber überzeugten die Laval-Gegner - Pétains Privatsekretär du Moulin de Labarthète, Darlan, Bouthillier, Baudouin, Peyrouton, Alibert und Huntziger - den Staatschef, daß er Gefahr laufe, während der Feierlichkeiten Opfer einer Intrige zu werden. Es wurde gemunkelt, der stellvertretende Ministerpräsident und Marcel Déat wollten eine ultra-kollaborationistische Regierung bilden ${ }^{150}$. Was immer daran stimmte oder frei erfunden war - das Maß war voll: Laval mußte demissionieren und wurde unter Hausarrest gestellt. Déat, der im Euvre nicht mit Kritik an Teilen der Vichy-Regierung sparte, wurde auf Betreiben des Generaldelegierten de La Laurencie in Paris festgenommen, jedoch wenige Stunden später nach wütenden Protesten Abetz' wieder auf freien Fuß gesetzt ${ }^{151}$. Ankunft und Beisetzung des Sarkophags am Abend des 14. Dezember, bei Schneeregen und Fackelschein, gerieten darüber völlig zur Nebensache. Die Bevölkerung nahm keinerlei Notiz ${ }^{152}$; Abetz, sichtlich geschockt, blieb nicht viel mehr zu tun, als vor der Presse und bei einem Empfang in der Botschaft trotzig darauf hinzuweisen, daß diese noble Geste „mitten im Krieg“ das spezielle Verdienst Pierre Lavals sei, des Garanten der deutsch-französischen Zusammenarbeit ${ }^{153}$. Als Vertreter Vichys waren Admiral Darlan und General Laure anwesend. Sie bekamen schwere Vorwürfe zu hören, kaum daß die Feierlichkeiten vorüber waren. Es gebe Mitarbeiter Pétains, die im Solde Englands ständen, wetterte Abetz, drohte mit Vergeltungsmaßnahmen bis hin zur Besetzung Restfrankreichs und betonte, das Reich habe kein Vertrauen in eine französische Regierung ohne Laval ${ }^{154}$.

148 Sowohl Abetz (Das offene Problem, S. 181) als auch Benoist-Méchin (A l'épreuve du temps, 2, S. 37) reklamierten für sich, die Idee für dieses Unterfangen schon im Herbst 1938 in Berlin vorgetragen zu haben.

149 Beide hielten die Deutsche Botschaft ständig auf dem laufenden. Schleier, „Der 13. Dezember", pag. 7: „Wir rechneten also fest damit, daß die Feier am 15. Dezember wie geplant vor sich gehen würde."

150 Darlan, Lettres et notes, S. 204.

151 Auszüge aus einem Bericht de La Laurencies vom 18. 4. 1941, „Les journées historiques de décembre 1940“; AN, AJ 72/249. Déat, Mémoires politiques, S. $582 \mathrm{f}$. Brender, Kollaboration, S. $111 \mathrm{ff}$.

152 KTB Halder, II, S. 232 (Eintrag vom 15. 12. 1940).

153 Aujourd'hui, 15. 12. 1940; Brinon, Mémoires, S. 57. Déat unkte: „Sont-ce les funérailles d'une politique?" Mémoires politiques, S. 585.

154 Aufzeichnungen Darlans über drei Unterredungen mit Abetz am 15. und 16. Dezember in Paris; Lettres et notes, Nr. 146-148. Anmerkung Schleiers: „Es war uns zu diesem Zeitpunkt nicht bekannt, daß Darlan selbst eine der treibenden Kräfte bei der Ausbootung von Laval gewesen war.“ („Der 13. Dezember“, pag. 18) 
Damit ließ es der Botschafter keineswegs bewenden. Am 16. Dezember fuhr er nach Vichy, begleitet von bewaffneten SS-Leuten, die als "deutliche Spitze" gegen die „zweifelhafte Rolle“ französischer Sicherheitsorgane am 13. gedacht waren ${ }^{155}$. In mehreren Unterredungen mit Pétain wiederholte er seine Vorwürfe und Verdächtigungen, nannte die jüngsten Ereignisse „ein Verbrechen an Frankreich" und stellte „auftragsgemäß“ die Berliner Forderungen zur künftigen Zusammensetzung der französischen Regierung: Laval sollte umgehend rehabilitiert und mit dem Innenressort betraut werden, Flandin den Posten des Außenministers bekleiden, Laurencie ebenso wie einige Minister weichen und ein Direktorium DarlanHuntziger-Flandin-Laval die politischen Geschäfte leiten. Die Gespräche wurden in einer hochgradig erregten Atmosphäre geführt. Pétain soll nicht weniger als fünfmal mit Rücktritt, Abetz andauernd mit seiner sofortigen Abreise gedroht haben. Der zwischendurch herbeizitierte Laval ging laut Abetz' Bericht wie ein Stier auf den greisen Staatschef los, bezichtigte ihn der Unaufrichtigkeit und des doppelten Spiels mit England 156 . Pétain indes blieb fest und begründete unter Hinweis, daß seine Würde und Autorität „ernstlich Schaden nehmen" würden, in einem Brief an Hitler seine Weigerung, den Geschaßten postwendend erneut zu berufen; er konzedierte lediglich die Ablösung Laurencies durch Brinon ${ }^{157}$. Als Abetz schließlich nach Paris zurückkehrte, schloß sich Laval seiner Wagenkolonne an, womit er sich in den Schutz der Besatzer flüchtete, was selbst einen so überzeugten Kollaborateur wie Brinon peinlich berührte ${ }^{158}$.

In einer wahren Ergebenheitsadresse an Hitler dankte Laval am 20. Dezember für die „Befreiung“ aus den Händen seiner Landsleute ${ }^{159}$. Abetz trug derweil grimmigen Zweckoptimismus zur Schau. Es sei ein „Geschenk des Himmels“, sagte er einem Mitglied der Waffenstillstandskommission, daß sich die „ernsten antideutschen Strömungen" in Vichy demaskiert hätten. Nach Berlin kabelte er, die hierdurch heraufbeschworene Krise gestatte ein unmittelbares Eingreifen in die französische Innenpolitik. In den kommenden Wochen müßten sämtliche Druckmittel der Besatzungsmacht „rücksichtslos eingesetzt werden, um den $\mathrm{Ha}$ sardeuren des 13. Dezember deutlich zu machen, welche unbeschreibliche Dummheit sie begangen haben ". Er selbst sorgte schnurstracks dafür, daß die Demarkationslinie für französische Regierungsmitglieder, Staatsbeamte und Militärs vorerst unpassierbar wurde, und die von ihm gelenkte Pariser Presse feuerte aus vollen Rohren gegen mißliebige Personen in Vichy ${ }^{160}$. An Feindbildern war kein

155 Aufzeichnung Schuchardt vom 18. 12. 1940, „Ergebnis der Reise des Botschafters Abetz nach Vichy“; AN, AJ 40/1215. Schleier behauptet, Abetz habe die Eskorte nur auf sein Drängen hin als Vorsichtsmaßnahme akzeptiert; „Der 13. Dezember“ ${ }^{\circ}$, pag. 19.

156 Bericht Abetz' vom 18. 12. 1940; ADAP, D XI.2, Nr. 531. Amt Ausl./Abw. an Chef OKW, 30. Dezember ( ${ }_{n}$ Nach Angaben von Botschafter Abetz ${ }^{c}$ ); AN, AJ 40/1215. Auch die im folgenden wiedergegebenen Äußerungen von Abetz stammen aus diesen beiden Dokumenten.

157 Abetz an Auswärtiges Amt, 18. 12. 1940, mit deutscher Übersetzung des Pétain-Briefs; ADAP, ebenda, Nr. 530.

158 Notizen Brinons; AN, 411 AP 6.

159 Enthalten in Abetz-Memorandum 1943, pag. $49 \mathrm{f}$

160 Vgl. Beschwerde Flandins bei Brinon, 6. 1. 1941, Bericht Brinons vom 15. Januar; MAE, Vichy-Europe, Y, Bd. 289. 
Mangel. Englische Agenten und vor allem die Action Française galten Abetz als Drahtzieher beim Sturz Lavals; speziell die AF habe „nur das eine Interesse, sämtliche Schlüsselstellungen der Regierung, der Verwaltungen, der Erziehung mit Männern zu besetzen, die Frankreich so schnell als möglich für einen militärischen Widerstand gegen Deutschland reif machen“. Zwar schätzte er den Marschall selbst als „aufrichtig“ ein, doch sei er geistig und charakterlich altersschwach geworden - „und um ihn herum sind nur ausgekochte jesuitische Lügner". Kein gutes Haar ließ der Botschafter am neuen Außenminister PierreEtienne Flandin, der „mit dreister Stirn behauptete, von nichts gewußt zu haben“; seine Ernennung ziele nicht zuletzt auf bessere Beziehungen zu England ${ }^{161}$. Mit wem aber war künftig zu schirren? Einzig Darlan erschien Abetz noch als eine „im deutschen Sinne vertrauenswürdige Persönlichkeit [...] Sonst ist kein einziger Mann vorhanden, der verspricht, bei der Stange zu bleiben." Wie sehr Ribbentrops Statthalter auf Pierre Laval fixiert war, offenbart seine Behauptung, der Entlassene sei der einzige volksverbundene Minister des ganzen Kabinetts gewesen, das in der Bevölkerung überhaupt nur wegen des Kollaborationsgedankens geduldet werde. „Das ist nicht richtig!“ schüttelte Halder über derlei Unsinn das Haupt. Der Wahrheit sehr viel näher kam seine Erkenntnis, die ,Palastrevolution“ in Vichy sei nicht zuletzt dadurch ausgelöst worden, „daß Laval infolge der schwankenden Haltung unserer Politik keine Erfolge aufzeigen konnte" ${ }^{162}$.

Die ganze verbale Kraftmeierei verdeckte nur dürftig, daß Otto Abetz in seinem Bemühen, die Beziehungen beider Länder auf neue Grundlagen zu stellen, einen schweren, vielleicht schon entscheidenden Rückschlag erlitten hatte. Die Kollaboration auf staatlicher Ebene welkte nach kurzer Scheinblüte nun monatelang dahin, ohne daß die Reichsregierung nennenswerte Anstrengungen unternahm, das brachliegende Feld zu beackern. Im Gegenteil: Hitler erklärte bündig, Deutschland sei aufgrund der jüngsten Vorkommnisse zu nichts mehr verpflichtet, und dies sei gut $s^{163}$. Keitel beschied den für die Rüstungswirtschaft im OKW verantwortlichen General Thomas am 10. Januar 1941, es bestehe „nicht mehr die Absicht, durch politische Absprachen oder Zusicherungen an die französische Regierung von uns aus auf eine Klärung der künftigen Zusammenarbeit hinzuwirken [...]. Den offensichtlichen Bemühungen von Vichy, den durch Entlassung Lavals abgerissenen Faden nun wieder anzuknüpfen, zeigen wir politisch einstweilen die kalte Schulter. "164 Erst im Mai 1941 kam ein weiterer Anlauf zustande, im Zuge der von Darlan unterzeichneten Pariser Protokolle. Sie faßten eine weitreichende militärische Kooperation im Mittelmeerraum und in Nordafrika ins Auge, waren jedoch spätestens mit Beginn des Rußlandfeldzugs Makulatur.

161 In den folgenden Monaten, bis zu seinem Rücktritt im Februar 1941, wurde Flandin von der Deutschen Botschaft nach Kräften geschnitten und diskreditiert. Vgl. Paxton, Vichy France, S. $101 \mathrm{ff}$.

162 KTB Halder, II, S. 241 (Eintrag vom 23. 12. 1940) und S. 234 (16. Dezember).

163 KTB OKW, Bd. 1, S. 256 (Eintrag vom 9. 1. 1941).

164 Zitiert bei Jäckel, Frankreich, S. 152. 
Am Silvesterabend des Jahres 1940 lud das Ehepaar Abetz zu einem rauschenden Fest in die Rue de Lille. Das Botschaftsgebäude war hell erleuchtet, der Champagner floß in Strömen. Corinne Luchaire wähnte den Gastgeber auf dem Gipfel seiner persönlichen Macht angelangt ${ }^{165}$. Doch hinter der strahlenden Fassade quollen in den folgenden Wochen Wut und Enttäuschung unverhüllt hervor ${ }^{166}$. Der wichtigsten Stütze auf französischer Seite beraubt und erneut im V1sier deutscher Kollaborationsgegner, sah Abetz seinen Kurs ernstlich gefährdet. Er tat in dieser Situation, was er seit den Anfängen der Dienststelle Ribbentrop virtuos beherrschte, und suchte einmal mehr möglichst viele Franzosen vor den Karren zu spannen. Mit Beginn des Jahres 1941 wurden unter Kuratel der Botschaft zahlreiche politische Parteien und Sammlungsbewegungen im besetzten Gebiet zugelassen, die eine radikale Variante der Kollaboration - den sogenannten Kollaborationismus - vertraten und eine ständige Opposition gegen Vichy bildeten, mit Laval als Galionsfigur einer potentiellen Gegenregierung. Ihre Mitglieder gefielen sich als Propagandisten und Handlanger der Besatzungsmacht, in der "Légion des volontaires français contre le bolchevisme" sogar als Soldaten an der Ostfront. Sie sollten, von den Besatzern mit beträchtlichen finanziellen Mitteln unterstützt, der Kollaboration und der Integration in Hitlers Europa einen populären Anstrich geben, waren aber zugleich so verschieden und uneins in ihren Vorstellungen vom künftigen Vaterland, daß die Abetzsche Maxime, mit verteilten Rollen zu spielen und ein politisch geschlossenes Frankreich zu verhindern, nie ins Wanken geriet ${ }^{167}$.

165 C. Luchaire, Ma drôle de vie, S. 139.

166 Aufschlußreich sind in diesem Zusammenhang die Aufzeichnungen des Verbindungsoffiziers zwischen Militärbefehlshaber und Botschaft, Major i.G. Schuchardt, den Schleier als "sehr loyal und bemüht“ schätzte (PA/AA, Nachl. Schleier/IV.4, „Militärbehörden“), über die politischen Morgenbesprechungen in der Rue de Lille. Am 29. 1. 1941 notierte er: „Der französischen Regierung soll klargemacht werden, daß der Weg der Kollaboration nur $100 \%$ ig oder gar nicht gegangen werden kann. [...] Sprachregelung gegenüber Franzosen: Die Leute in Vichy sind süffisant, unzuverlässig und eitel; mit solchen Leuten kann man keine Politik machen." - Über eine Unterredung mit Abetz vom 30. Januar: „Der Kampf gegen die Vichy-Regierung - vornehmlich gegen den Saboteur Flandin wird mit allen Mitteln geführt [...] Im wesentlichen gelten nur noch die Bestimmungen des Waffenstillstandsvertrags." Deutlich zum Vorschein kommt das tiefe Mißtrauen des Abetz-Stabes gegen die führenden Leute in Vichy: Flandin galt „praktisch als englischer Agent" (8. Februar), Pétain neuerdings als verschlagen und bauernschlau („Die Ansicht über das Charakterbild des Marschalls beginnt sich in der Botschaft zu wandeln"; 10 . Februar), und selbst bezüglich Darlans „Zuverlässigkeit" tauchten bald die ersten Zweifel auf (12. Februar). AN, AJ 40/1202, Dossier 3.

$167 \mathrm{Zu}$ den wichtigsten kollaborationistischen Parteien zählten Rassemblement national populaire (RNP, Déat), Parti populaire français (PPF, Doriot) und Mouvement social révolutionnaire (MSR, Deloncle). Einzelheiten und Überblick bei Ory, Les collaborateurs; Gordon, Collaborationism in France; Amouroux, Les beaux jours des collabos; Philippe Burrin, Le Collaborationnisme, in: Azéma/ Bédarida (Hrsg.), La France des années noires, 1, S. 363-383; zur Funktion der Kollaborationsparteien im deutschen Kalkül Brender, Kollaboration, S. $287 \mathrm{f}$. 